\title{
A Six-Gene Signature Predicts Survival of Adenocarcinoma Type of Non-Small-Cell Lung Cancer Patients: A Comprehensive Study Based on Integrated Analysis and Weighted Gene Coexpression Network
}

\author{
Hui Xie ${ }^{1,2}$ and Conghua Xie $\mathbb{D}^{1,2}$ \\ ${ }^{1}$ Department of Radiation and Medical Oncology, Zhongnan Hospital of Wuhan University, Wuhan, China \\ ${ }^{2}$ Hubei Key Laboratory of Tumor Biological Behaviors, Zhongnan Hospital of Wuhan University, Wuhan, China \\ Correspondence should be addressed to Conghua Xie; chxie_65@whu.edu.cn
}

Received 31 May 2019; Accepted 18 November 2019; Published 4 December 2019

Academic Editor: Yun-Peng Chao

Copyright (C) 2019 Hui Xie and Conghua Xie. This is an open access article distributed under the Creative Commons Attribution License, which permits unrestricted use, distribution, and reproduction in any medium, provided the original work is properly cited.

\begin{abstract}
Background and Goals. To identify a multigene signature model for prognosis of non-small-cell lung cancer (NSCLC) patients, we first found 2146 consensus differentially expressed genes (DEGs) in NSCLC overlapped in Gene Expression Omnibus (GEO) and TCGA lung adenocarcinoma (LUAD) datasets using integrated analysis. We constructed a weighted gene coexpression network (WGCN) using the consensus DEGs and identified the module significantly associated with pathological M stage and consisted of 61 genes. After univariate Cox regression analysis and subsequent stepwise model selection by the Akaike information criterion (AIC) and multivariate Cox hazard model analysis, an mRNA signature model which calculated prognostic score was generated: prognostic score $=\left(-0.2491 \times \mathrm{EXP}_{\mathrm{RRAGB}}\right)+\left(-0.0679 \times \mathrm{EXP}_{\mathrm{RSPH} 9}\right)+\left(-0.2317 \times \mathrm{EXP}_{\mathrm{RPS} 6 \mathrm{KL} 1}\right)+\left(-0.1035 \times \mathrm{EXP}_{\mathrm{RXFP} 1}\right)+0.1571 \times$ $\mathrm{EXP}_{\mathrm{RRM} 2}+0.1104 \times \mathrm{EXP}_{\mathrm{RTL} 1}$, where EXP is the fragments per kilobase million (FPKM) value of the mRNA included in the model. The prognostic model separated NSCLC patients in the TCGA-LUAD dataset into the low- and high-risk score groups with a median prognostic score of 0.972 . Higher scores predicted higher risk. The area under ROC curve (AUC) was 0.994 or 0.776 in predicting the 1- to 10-year survival of NSCLC patients. The prognostic performance of this prognostic model was validated by an independent GSE1 1969 dataset of NSCLC adenocarcinoma with AUC values between 0.822 and 0.755 in predicting 1- to 10-year survival of NSCLC. These results suggested that the six-gene signature functioned as an independent biomarker to predict the overall survival of NSCLC adenocarcinoma.
\end{abstract}

\section{Introduction}

Lung cancer (LC) is one of the leading causes of cancerassociated deaths worldwide $[1,2]$. Non-small-cell lung cancer (NSCLC) accounts for $85 \%$ of all lung cancer cases [3]. Approximately $50 \%$ NSCLC is adenocarcinoma and $40 \%$ NSCLC belong to squamous cell carcinoma. Complete surgical resection is the most effective therapy for patients in the early stage, and adjuvant chemotherapy (ACT) is the standard treatment for patients in stage II-III. However, the relapse and death rates remain high. A multiparameter molecular signature provides wider insights into the heterogeneous nature of cancer including NSCLC and may more reliably predict survival and benefit from chemotherapy of cancer patients than a single prognostic biomarker and/or staging system. It is important to establish prognostic gene signatures that reflect the nature of NSCLC from multiple tiers of mechanisms.

Prognostic signatures based on gene expression profiles for NSCLC have been generated in several studies. A 14-gene signature can predict survival in resected nonsquamous NSCLC [4], identify patients at high risk of mortality despite small, node-negative lung tumors [5], improve identification of patients at risk for recurrence in early-stage NSCLC [6], 
and predict benefit from adjuvant chemotherapy for very early stage NSCLC, which is superior over current National Comprehensive Cancer Network (NCCN) criteria at identifying high-risk patients [7]. A 15-gene signature can differentiate high- and low-risk subgroups with significantly different overall survival and is prognostic for both adenocarcinoma and squamous cell carcinoma cases [8]. $\mathrm{GeneFx}^{\circledR}$ Lung is a multigene RNA expression signature that classifies early-stage NSCLC patients as high-risk or low-risk for disease recurrence and predicts overall survival [9]. A 6gene signature including ABCC4, ADRBK2, KLHL23, PDS5A, UHRF1, and ZNF551 is identified to be the independent prognostic factor for overall survival [10]. A 10gene Yin Yang expression ratio signature (YMR) based on two groups of genes with opposing function significantly can separate high- and low-risk patients with stage IA or IB adenocarcinoma and squamous cell carcinomas of all stages. The YMR signature can also predict the benefit of adjuvant chemotherapy in high-risk patients with stage I NSCLC [11]. A 17-gene panel consisting of genes involved in epithelialmesenchymal transition (EMT), hypoxia response, glycometabolism, and epigenetic modifications for non-small-cell lung cancer prognosis has recently been identified through integrative epigenomic-transcriptomic analyses. It can clearly stratify NSCLC patients with significant differences in overall survival [12]. These gene signatures contribute to preclinical and clinical treatment of NSCLC. However, additional gene signatures are needed for accurate prognosis of NSCLC because of its complexity.

In this study, we first identified genes significantly associated with pathological $\mathrm{M}$ stage based on weighted gene coexpression network analysis (WGCNA) using differentially expressed genes overlapped in both Gene Expression Omnibus (GEO) datasets and the TCGALAUD dataset. We then selected genes significantly correlated with the overall survival of NSCLC patients among above genes according to a univariate Cox regression analysis and identified a 6-gene signature for prognosis of NSCLC based on a multivariate Cox hazard model analysis. We characterized the prognostic performance of the 6-gene signature using TCGA-LAUD dataset and validated it in an independent GSE dataset of NSCLC adenocarcinoma. Our findings suggested that the 6-gene signature is a prognostic marker for NSCLC adenocarcinoma.

\section{Methods}

2.1. Datasets and Workflow of Data Analysis. A total of 14 Gene Expression Omnibus (GEO) datasets regarding NSCLC were collected, including GSE19188, GSE30219, GSE10072, GSE7670, GSE2514, GSE32863, GSE21933, GSE40275, GSE12472, GSE80796, GSE8500, GSE85841, GSE19027, and GSE11969. The TCGA-LUAD RNAseq data and clinical data (level 3) of the NSCLC and ANT (adjacent normal tissue) samples were downloaded from the TCGA data portal (up to June 29, 2018) (Table 1) [13-15]. These datasets were processed and analyzed by following the workflow in Figure 1. This workflow was set up based on the published literature $[16,17]$.
2.2. GEO Datasets Processing and Integrated Analysis. The 13 raw GEO datasets (GSE19188, GSE30219, GSE10072, GSE7670, GSE2514, GSE32863, GSE21933, GSE40275, GSE12472, GSE80796, GSE8500, GSE85841, and GSE19027) were subjected to a quantitative and objective quality control using the MetaQC software package according to standardized mean ranks and principal component analysis (PCA) biplots [18, 19]. The resultant GEO datasets were designated as the training set. The training dataset was processed individually using the LIMMA (linear models within the microarray analysis) software package with $\log _{2}$ transformation and annotated by converting different probe IDs to their respective gene symbols. Duplicate gene expression values were averaged. Datasets from studies that screened differentially expressed mRNAs between human NSCLC and ANT samples were selected and combined. The MetaOmics software package (http://www.pitt.edu/ $\sim$ tsengweb/MetaOmicsHome.htm) was used to integrate and analyze the GEO datasets [18].

The DEGs between NSCLC and ANT were identified by analyzing the training set using the MetaDE software package by setting the mean and standard deviation (SD) filter thresholds at $10 \%$ to filter minor changes in gene expression levels [20]. Meta-analysis was performed using Fisher's method. The modified $t$ test and the permutation method by summarizing - $\log (P$ value $)$ across studies and running 300 permutations $\left(N_{\text {Permutations }}=300\right)$ were used to extrapolate the $P$ values [21]. $P$ values less than 0.05 were considered statistically significant for the DEGs. The heatmaps were generated to illustrate the expression patterns of DEGs [20].

2.3. TCGA-LUAD Dataset Processing and the Consensus DEGs. The TCGA-LUAD dataset was used as the test set to verify the results from the training set. Clinical information (American Joint Committee on Cancer pathological TNM stage, gender, age at initial pathological diagnosis and histological type, especially survival status, and time to latest follow-up) was screened to remove cases with incomplete clinical traits or gene expression information and resulted in 515 cases. The TCGA-LUAD DEGs were analyzed using an empirical Bayes approach within the LIMMA software package. The DEGs of the test set with a $\mid \log _{2}$ fold change (FC) $\mid \geq 0.5$ and an adjusted $P$ value less than 0.05 were selected for subsequent analysis. An overlapping gene set by selecting common official gene symbols in both the training and test sets was created as the consensus DEGs.

\subsection{Weighted Gene Coexpression Network Construction.} The consensus DEGs were subjected to WGCNA [14, 22, 23]. The scale-free gene coexpression networks were constructed using the clinical features and prognostic information of TCGA-LUAD dataset and the WGCNA software package [15].

The appropriate soft threshold power was automatically estimated and generated for the standard scale-free network. The weighted adjacency matrix was constructed using 
TABLE 1: Characteristics of the public microarray datasets used in this study.

\begin{tabular}{|c|c|c|c|c|}
\hline Study & Species/array platform & Samples & Number of samples & Set \\
\hline GSE19188 & $\begin{array}{l}\text { [HG-U133_Plus_2] Affymetrix Human } \\
\text { Genome U133 Plus 2.0 Array(GPL570) }\end{array}$ & $\begin{array}{l}\text { NSCLC vs. control } \\
\text { tissue }\end{array}$ & $\begin{aligned} \text { NSCLC }= & 91(\text { LUAD 45, LUSC 46), control } \\
& \text { tissue }=65, \text { total }=156\end{aligned}$ & $\begin{array}{c}\text { Training } \\
\text { set }\end{array}$ \\
\hline GSE30219 & $\begin{array}{l}\text { [HG-U133_Plus_2] Affymetrix Human } \\
\text { Genome U133 Plus } 2.0 \text { Array(GPL570) }\end{array}$ & $\begin{array}{l}\text { NSCLC vs. control } \\
\text { tissue }\end{array}$ & $\begin{array}{c}\text { NSCLC }=293, \text { control tissue }=14, \\
\text { total }=307\end{array}$ & $\begin{array}{c}\text { Training } \\
\text { set }\end{array}$ \\
\hline GSE10072 & $\begin{array}{c}\text { [HG-U133A] Affymetrix Human Genome } \\
\text { U133A Array (GPL96) }\end{array}$ & $\begin{array}{r}\text { NSCLC } \mathrm{v} \\
\text { tiss }\end{array}$ & $\begin{array}{c}\text { NSCLC }=58(\text { LUAD } 58), \text { control } \\
\text { tissue }=49, \text { total }=107\end{array}$ & $\begin{array}{c}\text { Training } \\
\text { set }\end{array}$ \\
\hline GSE7670 & $\begin{array}{c}\text { [HG-U133A] Affymetrix Human Genome } \\
\text { U133A Array (GPL96) }\end{array}$ & $\begin{array}{r}\text { NSCLC vs } \\
\text { tiss }\end{array}$ & $\begin{array}{r}\text { NSCLC }=28(\mathrm{~L} \\
\text { tissue }=3\end{array}$ & $\begin{array}{c}\text { Training } \\
\text { set }\end{array}$ \\
\hline GSE2514 & $\begin{array}{l}\text { [MG_U74Av2] Af } \\
\text { Genome U74A Versic }\end{array}$ & $\begin{array}{l}\text { NSCLC vs. control } \\
\text { tissue }\end{array}$ & NSCLC $=20$, control tissue $=19$, total $=39$ & $\begin{array}{c}\text { Training } \\
\text { set }\end{array}$ \\
\hline GSE32863 & $\begin{array}{r}\text { Illumina HumanWG-6 v } \\
\text { beadchip (GPL6 }\end{array}$ & $\begin{array}{l}\text { NSCLC vs. control } \\
\text { tissue }\end{array}$ & $\begin{array}{r}\text { NSCLC }=58 \\
\text { tissue }=\end{array}$ & $\begin{array}{c}\text { Training } \\
\text { set }\end{array}$ \\
\hline GSE21933 & Phalanx Human OneArray (GPL6254) & $\begin{array}{l}\text { NSCLC vs. control } \\
\text { tissue }\end{array}$ & $\mathrm{NSCLC}=21$, control tissue $=21$, total $=42$ & $\begin{array}{c}\text { Training } \\
\text { set }\end{array}$ \\
\hline GSE40275 & Human Exon 1.0 ST Array (GPL15974) & $\begin{array}{r}\text { NSCLC } \\
\text { tis }\end{array}$ & $\mathrm{NSCLC}=41$, control $\mathrm{t}$ & $\begin{array}{c}\text { Training } \\
\text { set }\end{array}$ \\
\hline GSE & $\begin{array}{l}\text { Agilent-012391 Whole Human Genome } \\
\text { Oligo Microarray G4112A (Feature } \\
\text { Number version) (GPL1708) }\end{array}$ & $\begin{array}{l}\text { NSCLC vs. control } \\
\text { tissue }\end{array}$ & $\begin{array}{c}\text { NSCLC }=35(\text { LUSC } 35), \text { control tissue }=28, \\
\text { total }=63\end{array}$ & $\begin{array}{c}\text { Training } \\
\text { set }\end{array}$ \\
\hline GSE 8 & $\begin{array}{c}\text { [HuGene-1_0-st] Affymetrix Human Gene } \\
\text { 1.0 ST Array [transcript (gene) version] } \\
\text { (GPL6244) }\end{array}$ & $\begin{array}{l}\text { NSCLC vs. control } \\
\text { tissue }\end{array}$ & $\begin{array}{c}\text { NSCLC }=309, \text { control tissue }=196, \\
\text { total }=505\end{array}$ & $\begin{array}{c}\text { Training } \\
\text { set }\end{array}$ \\
\hline GSE8500 & n 3.0 A1 (GPL3 & $\begin{array}{r}\text { NSCLC } \\
\text { tis }\end{array}$ & $\mathrm{NSCLC}=40, \mathrm{co}$ & $\begin{array}{l}\text { Training } \\
\text { set }\end{array}$ \\
\hline GSE85841 & $\begin{array}{c}\text { Agilent-067406 Human CBC } \\
\text { lncRNA + mRNA microarray V4.0 } \\
\text { (GPL20115) }\end{array}$ & $\begin{array}{l}\text { NSCLC vs. control } \\
\text { tissue }\end{array}$ & NSCLC $=8$, control tissue $=8$, total $=16$ & $\begin{array}{c}\text { Training } \\
\text { set }\end{array}$ \\
\hline GSE19027 & $\begin{array}{c}\text { [HG-U133A] Affymetrix Human Genome } \\
\text { U133A Array (GPL96) }\end{array}$ & $\begin{array}{l}\text { NSCLC vs. control } \\
\text { tissue }\end{array}$ & NSCLC $=21$, control tissue $=39$, total $=60$ & $\begin{array}{c}\text { Training } \\
\text { set }\end{array}$ \\
\hline $\begin{array}{l}\text { TCGA- } \\
\text { LUAD }\end{array}$ & Human Illumina HiSeq 2000 & $\begin{array}{l}\text { LUAD vs. control } \\
\text { tissue }\end{array}$ & $\mathrm{LUAD}=517$, control tissue $=59$, tota & Test set \\
\hline GSE11969 & $\begin{array}{l}\text { Agilent Homo sapiens } 21.6 \mathrm{~K} \text { custom array } \\
\text { (GPL7015) }\end{array}$ & Overall survival & $\begin{array}{c}\text { LUAD }=94, \text { Overall survival } \\
\text { information }=94\end{array}$ & $\begin{array}{l}\text { Validation } \\
\text { set }\end{array}$ \\
\hline
\end{tabular}

GSE, Gene Expression Omnibus accession number; TCGA, the Cancer Genome Atlas; NSCLC, non-small-cell lung cancer; LUAD, lung adenocarcinomal; LUSC, lung squamous cell carcinoma.

the power function $\mathrm{ADJ}_{m n}=\left|\mathrm{COR}_{m n}\right|^{\beta}\left(\mathrm{COR}_{m n}=\right.$ Pearson's correlation between gene $m$ and gene $n$, where $\mathrm{ADJ}_{m n}=$ adjacency between gene $m$ and gene $n$ and $\beta$ is the soft thresholding parameter, which was used to transform adjacencies and correlations into a topological overlap matrix (TOM). The corresponding dissimilarity was calculated as 1-TOM. Module identification was carried out with the dynamic tree cut method by hierarchically clustering the genes using 1-TOM as the distance measure with a deep split value of 2 and a minimum size cutoff 50 for the resulting dendrogram. Highly similar modules were marked by clustering and merged with a height cutoff 0.25 .

\subsection{Identification of Clinical Feature Modules and Efficacy} Evaluation of Pathological Stage Hub Genes. Module eigengenes (MEs), which are the first principal components in the PCA for each gene module, summarized the expression patterns of all genes into a single characteristic expression profile within a given module. The dynamic decision-making tree, node splitting method, and cluster analysis of the squared Euclidean distance were used to identify MEs related to these clinical features, especially those involved in the progression and prognosis of NSCLC. Modules with similar expression profiles were identified using the dynamic tree cut method. Highly similar modules were merged. Spearman's correlation analysis was carried out to confirm the object module, which was the most relevant module between the MEs and clinical traits. Depending on these, the module that had the highest absolute Spearman's correlation coefficient (PCC) value for the pathological stage and MEs was defined as the pathological stage module.

2.6. Identification, Characterization, and Validation of an mRNA Prognostic Model for NSCLC Patients. Association of genes in the pathological stage modules with survival of NSCLC patients was analyzed using a univariate Cox regression analysis. The genes with $P$ value $<0.05$ were selected. A stepwise model selection by the Akaike information criterion (AIC) was further performed to avoid overfitting to select a final list of genes. A multivariate Cox hazard model analysis was performed to generate an mRNA prognostic signature model, which calculated the prognostic score as follows: prognostic score $=\sum\left(C \times \mathrm{EXP}_{\mathrm{mRNA}}\right)$, where $\mathrm{EXP}$ is 


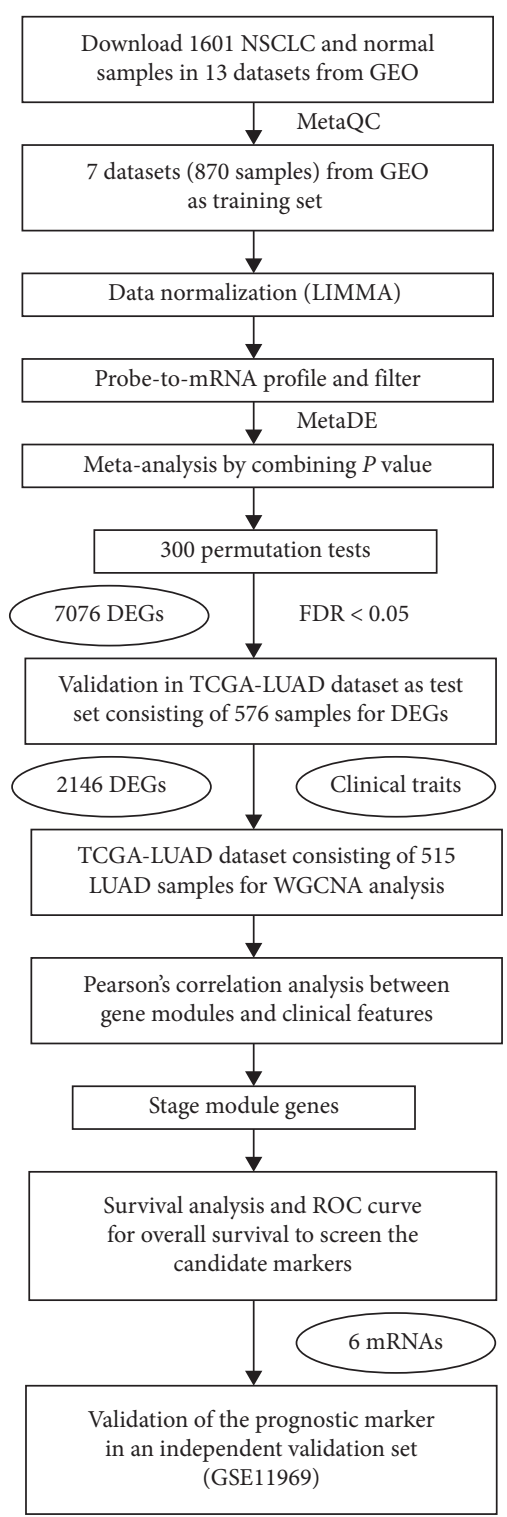

FIgURE 1: Workflow of the integrated analysis and WGCNA analysis of the NSCLC datasets. Figure 1 was reproduced from Sun et al. [16].

the fragments per kilobase million (FPKM) value of the mRNA and $C$ is the regression coefficient for the corresponding mRNA in multivariate Cox hazard model analysis. The median prognostic score of the training dataset was used to differentiate high-risk group and low-risk group. Higher scores predicted higher risk. The prognostic performance of the mRNA signature model was measured using receiver operating characteristic (ROC) curves by comparing the area under the respective ROC curves (AUC). The mRNA signature was examined for its association with patient survival. Finally, the mRNA signature model was validated with an independent data set GSE11969 of NSCLC adenocarcinoma. All reported $P$ values were two-sided. All analyses were carried out via the R/BioConductor (version 3.5.1). Survival curves and ROCs were generated by ggplot2, survival, and survivalROC packages.

\section{Results}

3.1. Identification of Consensus NSCLC DEGs in the Training Set and the Test Set. A total of 7 GEO datasets (GSE10072, GSE19188, GSE21933, GSE30219, GSE32863, GSE40275, and GSE7670) were selected from the 13 raw datasets after MetaQC quality control for subsequent analysis (Table 2 and Figure 2(a)). These datasets contained 590 NSCLC and 280 ANTs and were designated as the training set. In the training set, a total of 7373 DEGs were identified after filtering through the mean and standard deviation (SD) thresholds. A list of 7076 DEGs were subsequently obtained, and we eliminated batch effect after Fisher's $t$ test and 300 permutations (Figure 2(b)). Hierarchical clustering of the seven datasets in the training set using the 7076 DEGs distinguished NSCLC from ANT samples (Figure 3(a)). In the TCGA-LUAD dataset which contained 20501 mRNAs in 517 NSCLC samples and 59 ANT samples, a total of 3592 DEGs were identified and designated as the test set. The DEGs in the test set distinguished NSCLC from ANT samples in the 2-way hierarchical cluster (Figure 3(b)). A total of overlapped 2146 DEGs between the training set and the test set were identified and designated as the consensus DEGs (Figure 3(c)).

3.2. Coexpression Network Construction and Identification of Modules Associated with Clinicopathological Features. We constructed a weighted gene coexpression network (WGCN) using the 2146 consensus DEGs and clinical traits and prognostic information from 515 NSCLC patients in the TCGA-LUAD test set. The results showed that the connections between the genes in the WGCN were in line with a scale-free network distribution (Figures 4(a)-4(d)). Modules with similar expression profiles were identified using the dynamic tree cut method (Figures 5(a) and 5(b)). Highly similar modules were merged (Figure 5(b)). A total of 14 WGCN modules ranging from 54 to 607 genes in each module were generated (Figure 5(c)). We further analyzed association of modules with clinicopathological features to identify pathological stage modules using Spearman's correlation and Module eigengenes analysis. The results showed the lightcyan module was most significantly associated with pathological $M$ stage $(R=0.12, P=0.009)$, and this module contained 61 genes (Figure 5(c)).

3.3. Construction of an mRNA-Signature Prognostic Model and Characterization of Its Prognostic Performance Using NSCLC-LUAD. To investigate potential genes significantly associated with the survival of NSCLC patients, we performed a univariate Cox regression analysis using the lightcyan module genes. The results showed that the twelve genes RRM2, RPS6KL1, RTL1, RXFP1, RRM1, RTCD1, RRAGB, RSPH10B2, RRM2B, RSPH9, RXFP2, and RUNX1 were significantly correlated with the overall survival of NSCLC patients (Table 3). We further performed a stepwise model selection by the Akaike information criterion (AIC), and six genes RRAGB, RSPH9, RPS6KL1, RXFP1, RTL1, and RRM2 were selected. Multivariate Cox hazard model 
TABLE 2: Quality control of the training datasets.

\begin{tabular}{|c|c|c|c|c|c|c|c|c|}
\hline No. & Datasets & IQC & EQC & CQCg & CQCp & AQCg & AQCp & Rank \\
\hline 1 & GSE19188 & 8.56 & $2^{*}$ & 307.65 & 160.1 & $0.79^{*}$ & 54.72 & 2.33 \\
\hline 2 & GSE30219 & 4.43 & $2^{*}$ & 307.65 & 182.57 & $0.76^{*}$ & 71.49 & 2.58 \\
\hline 3 & GSE10072 & 9.76 & $2^{*}$ & 307.65 & 178.14 & $0.14^{*}$ & 49.61 & 3.67 \\
\hline 4 & GSE7670 & 6.48 & $1.7^{*}$ & 307.65 & 133.26 & $0.2^{*}$ & 43.06 & 4.75 \\
\hline 5 & GSE2514 & 3.66 & $1.53^{*}$ & 307.65 & 111.14 & $0.4^{*}$ & 22.46 & 5.67 \\
\hline 6 & GSE32863 & 5.73 & $1.7^{*}$ & 307.65 & 63.92 & $0.08^{*}$ & 32.71 & 5.75 \\
\hline 7 & GSE21933 & 4.43 & $1^{*}$ & 307.65 & 52.67 & $0.37^{*}$ & 23.99 & 6.08 \\
\hline 8 & GSE40275 & 3.96 & $1.53^{*}$ & 8.68 & 34.36 & $0.29^{*}$ & 21.19 & 7.50 \\
\hline 9 & GSE12472 & $0.24^{*}$ & $1.53^{*}$ & 7.06 & 44.83 & $0.32^{*}$ & 12.49 & 8.33 \\
\hline 10 & GSE80796 & $2.08^{*}$ & $1.05^{*}$ & $0.27^{*}$ & $2.32^{*}$ & $0.28^{*}$ & $1.38^{*}$ & 10.00 \\
\hline 11 & GSE8500 & 3.51 & $0.4^{*}$ & $0.38^{*}$ & 4.02 & $0.26^{*}$ & $0.06^{*}$ & 10.67 \\
\hline 12 & GSE85841 & $0.04^{*}$ & $0.62^{*}$ & $0.71^{*}$ & $0.31^{*}$ & $0.04^{*}$ & $0.26^{*}$ & 11.67 \\
\hline 13 & GSE19027 & $1.35^{*}$ & $0.39^{*}$ & $0^{*}$ & 7.83 & $0.03^{*}$ & $0.24^{*}$ & 12.00 \\
\hline
\end{tabular}

NSCLC, non-smal-cell lung carcinoma; GSE, GEO dataset; IQC, internal quality control indexes; EQC, external quality control indexes; CQCg and CQCp, consistency of differential expression quality control indexes for genes and pathways; AQCg and AQCp, accuracy quality control indexes for genes and pathways. ${ }^{*} P$ value not significant after Bonferroni correction.

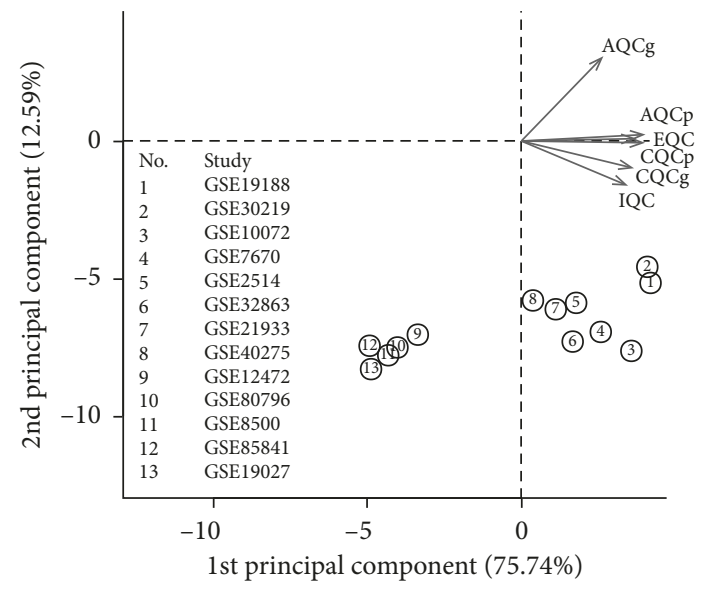

(a)

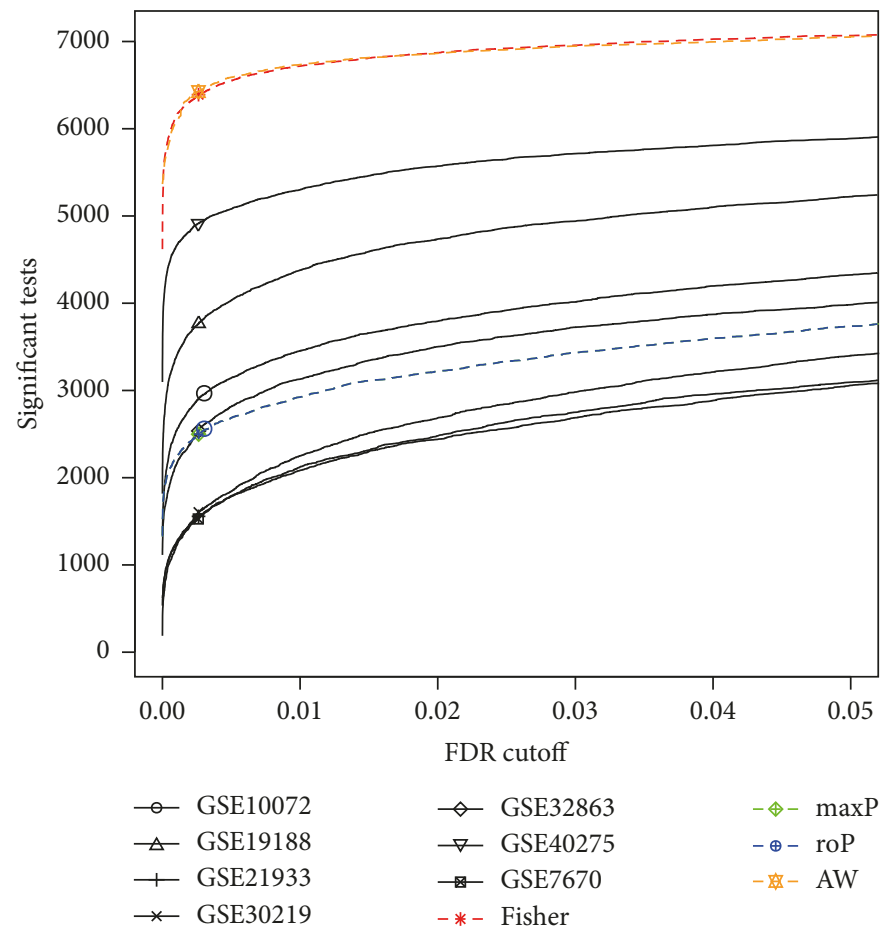

(b)

Figure 2: Meta-analysis of differentially expressed genes involved in NSCLC by combining $P$ values. (a) Principal component analysis (PCA) biplot of quality control measures in thirteen NSCLC studies. (b) The number of differentially expressed genes plotted as a function of false discovery rate (FDR) in the analysis of four different datasets and four different meta-analysis algorithms ( $\mathrm{maxP}$, minP, roP, and adaptively weighted statistic). Figure 2 was reproduced from Sun et al. [16].

analysis of association of these six genes with survival showed that RPS6KL1 and RXFP1 were independent factors associated with good overall survival in NSCLC patients, while RTL1 and RRM2 were independent factors associated with poor overall survival in NSCLC patients (Table 4). We generated an mRNA signature model which calculated the prognostic score: prognostic score $=\left(-0.2491 \times \mathrm{EXP}_{\text {RRAGB }}\right)$ $+\left(-0.0679 \times \mathrm{EXP}_{\mathrm{RSPH} 9}\right)+\left(-0.2317 \times \mathrm{EXP}_{\mathrm{RPS} 6 \mathrm{KL} 1}\right)+(-0.1035 \times$
$\left.\mathrm{EXP}_{\mathrm{RXFP} 1}\right)+0.1571 \times \mathrm{EXP}_{\mathrm{RRM} 2}+0.1104 \times \mathrm{EXP}_{\mathrm{RTL} 1}$, where $\mathrm{EXP}$ is the FPKM value of the mRNA included in the model.

We characterized the prognostic performance of the sixmRNA signature model using the TCGA-LUAD dataset. According to prognostic scores, the median score was 0.972 and we separated NSCLC patients into the low-risk group $(n=253)$ and the high-risk group $(n=253)$ (Figure $6(\mathrm{a}))$. The high-risk group had significantly shorter survival time or lower survival 


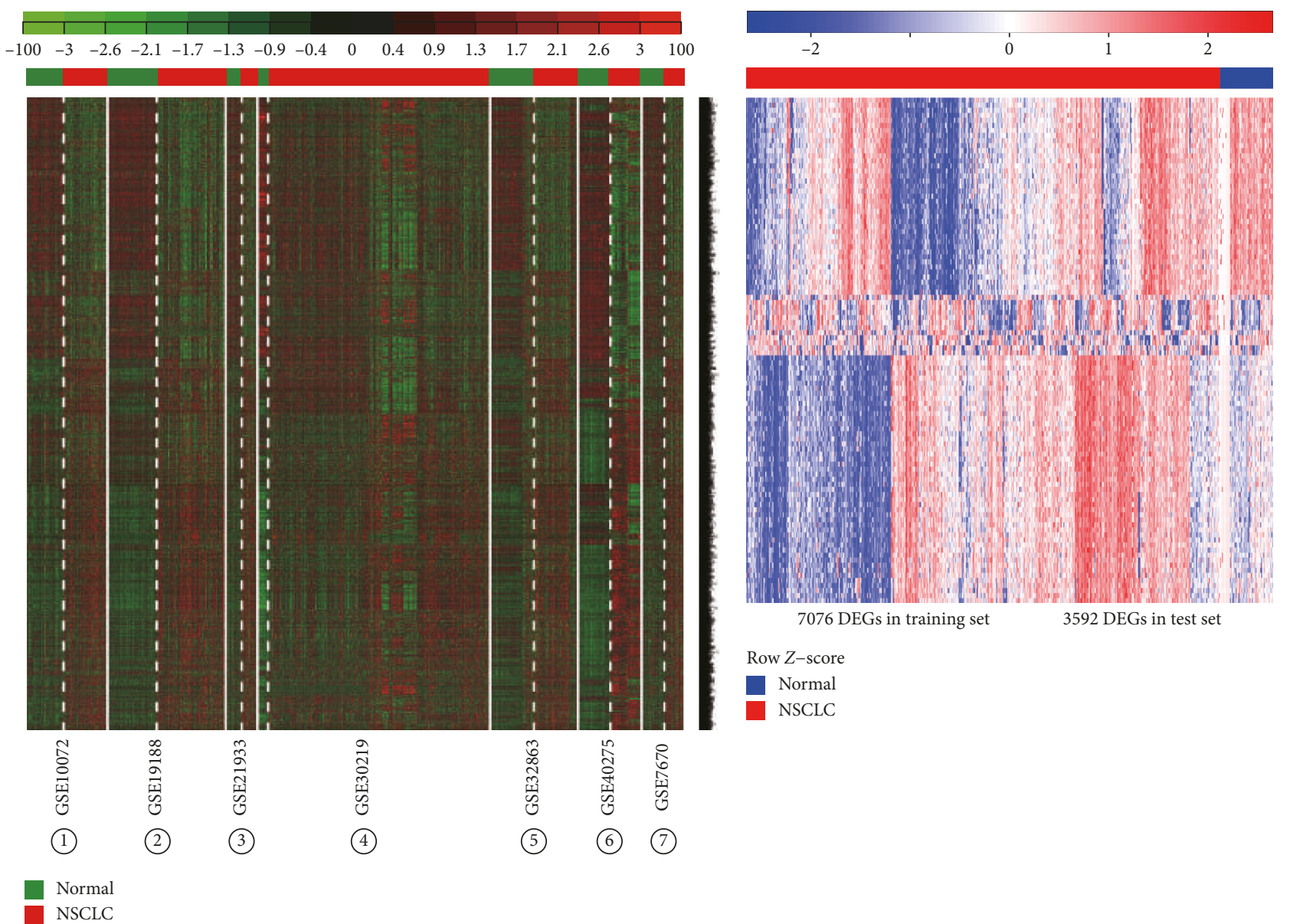

(a)

(b)

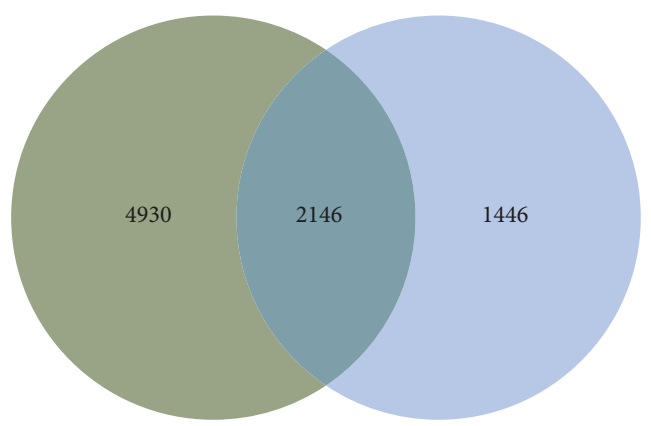

(c)

FIGURE 3: Identification of consensus DEGs in the training and the test datasets of NSCLC patients. (a) Heat map and two-way hierarchical clustering based on 7076 DEGs that were differentially expressed between NSCLC and ANT samples of the training set. ANT (green label) and NSCLC (red label) samples fell into separate clusters. (b) The 3592 DEGs NSCLC (red label) vs. ANT (blue label) of the TCGA-LUAD test set. Each column represents a sample, and each row represents the mRNA level. The color scale represents the raw $Z$-score ranging from blue (low expression) to red (high expression). Dendrograms beside each heat map correspond to the hierarchical clustering of the 3592 DEGs by the expression level. (c) A Venn diagram showing the overlap of DEGs detected in the training and test sets. Figure 3 was reproduced from Sun et al. [16].

probabilities than the low-risk group did (HR, 2.298; 95\% CI, 1.711-3.086; log-rank test $P=9.181 \times 10^{-9}$ ) (Figure 6(b)). The area under ROC curve (AUC) was 0.994 or 0.776 in predicting the 1 - to 10 -year survival of NSCLC patients (Figure 6(c)). High expression of RRAGB, RSPH9, RPS6KL1, and RXFP1 and low expression of RTL1 and RRM2 predicted good survival (Figures 6(d)-6(i)). The results suggested that the six-mRNA signature could predict the prognosis of NSCLC-LUAD.

3.4. Validation of the Prognostic Performance of the Six-mRNA Signature in NSCLC Adenocarcinoma. To validate the prognostic performance of the six-mRNA model for 


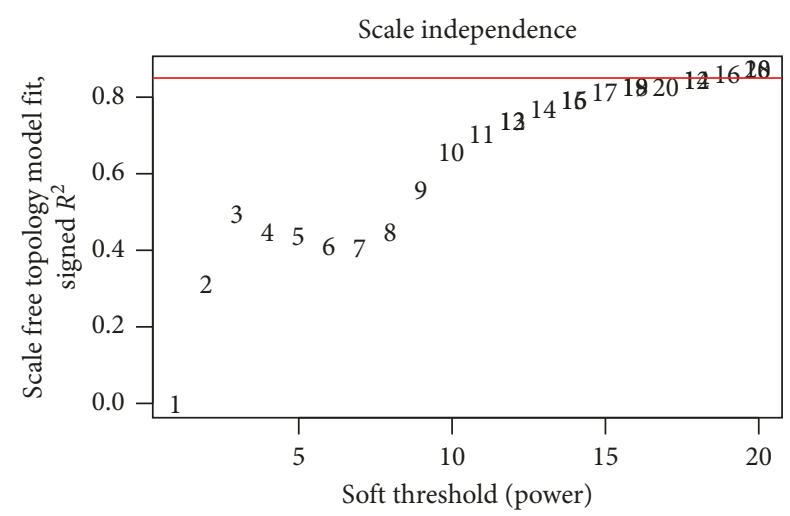

(a)

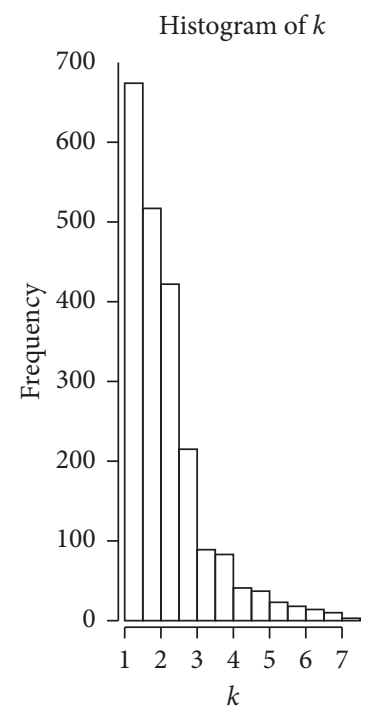

(c)

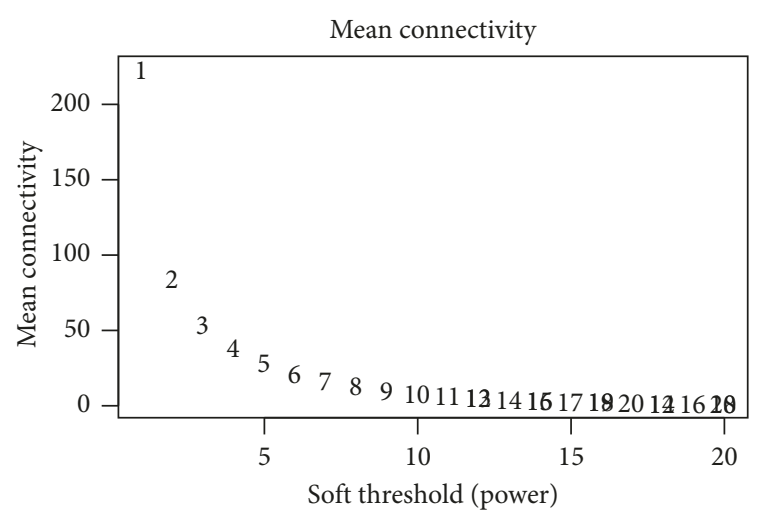

(b)

Check scale free topology

Scale $R^{2}=0.95$, slope $=-2.83$

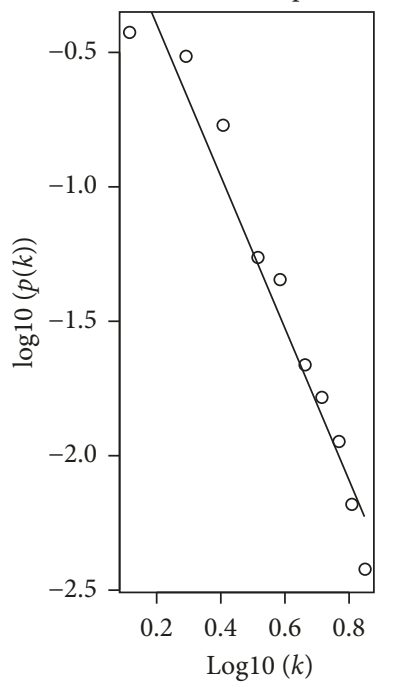

(d)

FIGURE 4: Determination of parameter $\beta$ of the adjacency function in the weighted gene correlation network analysis (WGCNA) algorithm. (a) Analysis of the scale-free fit index for various soft thresholding powers $\beta$. (b) Analysis of the mean connectivity for various soft thresholding powers. (c) Histogram of connectivity distribution when $\beta=19$. (d) Checking the scale-free topology when $\beta=19$. Figure 4 was reproduced from Sun et al. [16].

NSCLC, we measured the prognostic performance of this model using the validation dataset GSE11969 of NSCLC adenocarcinoma. The results showed that the patients were divided into the high-risk group $(n=47)$ and the low-risk group $(n=47)$ according to the risk scores and the median cutoff point (Figure 7(a)). The high-risk group had significantly shorter survival time or lower survival probabilities than the low-risk group did (HR, 3.286; 95\% CI, 1.79-6.03; log-rank test $P=0.00013$ ) (Figure 7(b)). The area under ROC curve in predicting 1 - to 10 -year survival of NSCLC was between 0.822 and 0.755 (Figure 7(c)). High expression of RRAGB, RSPH9, RPS6KL1, and RXFP1 and low expression of RTL1 and RRM2 expression predicted good survival of NSCLC patients (Figures 7 (d) $-7(\mathrm{i})$ ). These results were consistent with those of the test set (compare Figures 6 and 7), supporting that the six-mRNA signature could predict the prognosis of NSCLC adenocarcinoma.
3.5. Relative Expression Levels of RRAGB, RSPH9, RPS6KL1, RXFP1, RRM2, and RTL1 in NSCLC Tissues and the High- and Low-Risk Groups. Examination of the expression patterns of these signature mRNAs revealed that RRAGB, RSPH9, and RXFP1 mRNA levels were significantly lower and RPS6KL1, RTL1, and RRM2 mRNA levels were significantly decreased in NSCLC of TCGA-LUAD, compared with the normal control (Figure 8(a)). The expression levels of RRAGB, RSPH9, RPS6KL1, and RXFP1 were significantly lower and RTL1 and RRM2 mRNA levels were significantly higher in the high-risk group than those in the low-risk group in NSCLC of TCGALUAD (Figure 8(b)). The expression levels of RRAGB, RSPH9, RPS6KL1, RXFP1, and RTL1 mRNA were significantly lower and the RRM2 mRNA level was significantly higher in the high-risk group than those in the low-risk group in NSCLC adenocarcinoma of GSE11969 (Figure 8(c)). 


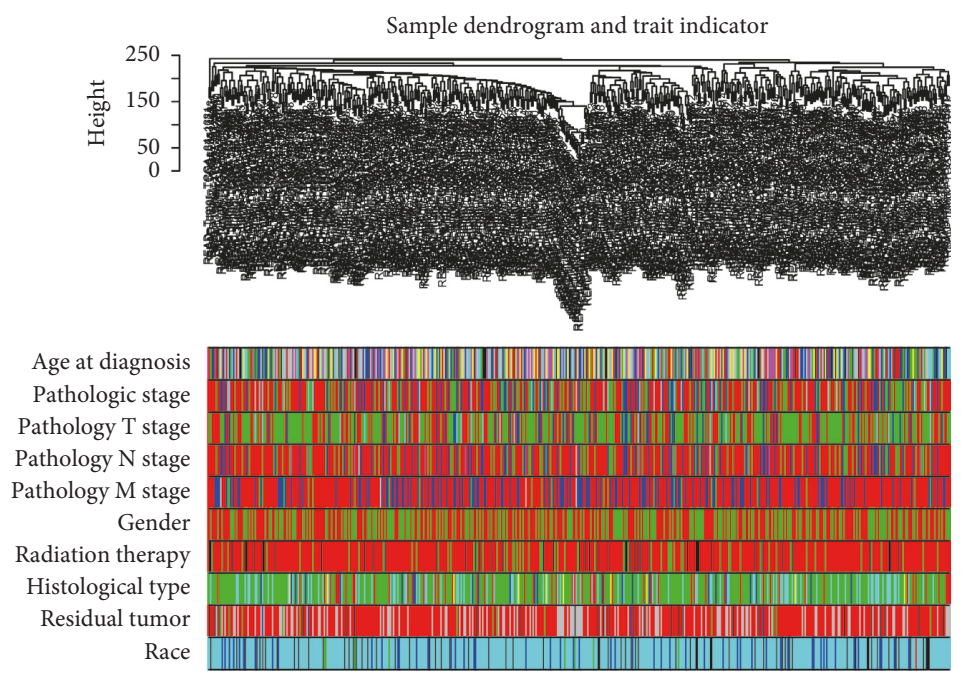

(a)

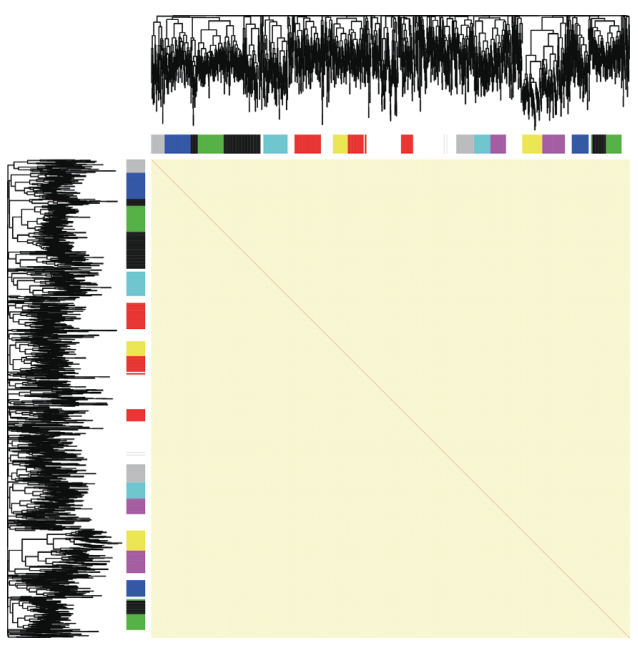

(b)

\begin{tabular}{|c|c|c|c|c|c|c|c|c|c|}
\hline \multicolumn{9}{|c|}{ Module-trait relationships } & \\
\hline MEblack & $\begin{array}{c}-0.0091 \\
(0.8)\end{array}$ & $\begin{array}{c}-0.0017 \\
(1)\end{array}$ & $\begin{array}{c}-0.013 \\
(0.8)\end{array}$ & $\begin{array}{c}-0.022 \\
(0.6)\end{array}$ & $\begin{array}{l}-0.074 \\
(0.09)\end{array}$ & $\begin{array}{c}0.039 \\
(0.4)\end{array}$ & $\begin{array}{c}-0.035 \\
(0.4)\end{array}$ & $\begin{array}{c}0.021 \\
(0.6)\end{array}$ & \\
\hline MEgreenyellow & $\begin{array}{c}0.046 \\
(0.3)\end{array}$ & $\begin{array}{l}0.027 \\
(0.5)\end{array}$ & $\begin{array}{l}0.05 \\
(0.3)\end{array}$ & $\begin{array}{r}0.027 \\
(0.5)\end{array}$ & $\begin{array}{c}0.049 \\
(0.3)\end{array}$ & $\begin{array}{l}0.00078 \\
(1)\end{array}$ & $\begin{array}{c}0.066 \\
(0.1)\end{array}$ & $\begin{array}{c}0.0055 \\
(0.9)\end{array}$ & \\
\hline MEtan & $\begin{array}{c}0.017 \\
(0.7)\end{array}$ & $\begin{array}{l}0.044 \\
(0.3)\end{array}$ & $\begin{array}{c}-0.0091 \\
(0.8)\end{array}$ & $\begin{array}{c}0.025 \\
(0.6)\end{array}$ & $\begin{array}{c}0.0015 \\
(1)\end{array}$ & $\begin{array}{c}-0.036 \\
(0.4)\end{array}$ & $\begin{array}{l}0.05 \\
(0.3)\end{array}$ & $\begin{array}{c}0.0094 \\
(0.8)\end{array}$ & \\
\hline MEblue & $\begin{array}{c}0.071 \\
(0.1)\end{array}$ & $\begin{array}{c}-0.038 \\
(0.4)\end{array}$ & $\begin{array}{l}0.077 \\
(0.08)\end{array}$ & $\begin{array}{l}-0.05 \\
(0.3)\end{array}$ & $\begin{array}{c}-0.058 \\
(0.2)\end{array}$ & $\begin{array}{c}0.0037 \\
(0.9)\end{array}$ & $\begin{array}{c}-0.015 \\
(0.7)\end{array}$ & $\begin{array}{l}0.079 \\
(0.07)\end{array}$ & -0.5 \\
\hline MEmidnightblue & $\begin{array}{c}-0.066 \\
(0.1)\end{array}$ & $\begin{array}{l}0.041 \\
(0.4)\end{array}$ & $\begin{array}{c}-0.039 \\
(0.4)\end{array}$ & $\begin{array}{l}-0.085 \\
(0.05)\end{array}$ & $\begin{array}{l}-0.095 \\
(0.03)\end{array}$ & $\begin{array}{c}-0.0021 \\
(1)\end{array}$ & $\begin{array}{c}0.011 \\
(0.8)\end{array}$ & $\begin{array}{l}0.087 \\
(0.05)\end{array}$ & \\
\hline MElightgreen & $\begin{array}{l}0.034 \\
(0.4)\end{array}$ & $\begin{array}{l}0.011 \\
(0.8)\end{array}$ & $\begin{array}{l}0.044 \\
(0.3)\end{array}$ & $\begin{array}{c}-0.0082 \\
(0.9)\end{array}$ & $\begin{array}{l}0.03 \\
(0.5)\end{array}$ & $\begin{array}{l}-0.039 \\
(0.4)\end{array}$ & $\begin{array}{c}-0.014 \\
(0.8)\end{array}$ & $\begin{array}{l}-0.06 \\
(0.2)\end{array}$ & \\
\hline MEpink & $\begin{array}{l}0.011 \\
(0.8)\end{array}$ & $\begin{array}{l}0.049 \\
(0.3)\end{array}$ & $\begin{array}{l}0.011 \\
(0.8)\end{array}$ & $\begin{array}{l}-0.04 \\
(0.4)\end{array}$ & $\begin{array}{c}0.033 \\
(0.5)\end{array}$ & $\begin{array}{l}-0.025 \\
(0.6)\end{array}$ & $\begin{array}{c}0.028 \\
(0.5)\end{array}$ & $\begin{array}{c}-0.014 \\
(0.8)\end{array}$ & \\
\hline MEmagenta & $\begin{array}{c}0.031 \\
(0.5)\end{array}$ & $\begin{array}{c}-0.037 \\
(0.4)\end{array}$ & $\begin{array}{c}0.031 \\
(0.5)\end{array}$ & $\begin{array}{c}0.074 \\
(0.1)\end{array}$ & $\begin{array}{c}0.017 \\
(0.7)\end{array}$ & $\begin{array}{c}-0.0043 \\
(0.9)\end{array}$ & $\begin{array}{c}-0.061 \\
(0.2)\end{array}$ & $\begin{array}{c}-0.046 \\
(0.3)\end{array}$ & \\
\hline MElightcyan & $\begin{array}{l}0.03 \\
(0.5)\end{array}$ & $\begin{array}{c}0.055 \\
(0.2)\end{array}$ & $\begin{array}{c}0.0099 \\
(0.8)\end{array}$ & $\begin{array}{c}0.12 \\
(0.009)\end{array}$ & $\begin{array}{l}0.02 \\
(0.7)\end{array}$ & $\begin{array}{l}0.01 \\
(0.8)\end{array}$ & $\begin{array}{c}-0.047 \\
(0.3)\end{array}$ & $\begin{array}{l}-0.04 \\
(0.4)\end{array}$ & \\
\hline MEbrown & $\begin{array}{c}-0.0012 \\
(1)\end{array}$ & $\begin{array}{c}-0.034 \\
(0.4)\end{array}$ & $\begin{array}{l}-0.015 \\
(0.7)\end{array}$ & $\begin{array}{c}0.054 \\
(0.2)\end{array}$ & $\begin{array}{c}-0.0094 \\
(0.8)\end{array}$ & $\begin{array}{l}-0.045 \\
(0.3)\end{array}$ & $\begin{array}{c}-0.066 \\
(0.1)\end{array}$ & $\begin{array}{c}0.042 \\
(0.3)\end{array}$ & \\
\hline MEyellow & $\begin{array}{l}0.01 \\
(0.8)\end{array}$ & $\begin{array}{c}-0.021 \\
(0.6)\end{array}$ & $\begin{array}{c}-0.0085 \\
(0.8)\end{array}$ & $\begin{array}{l}0.083 \\
(0.06)\end{array}$ & $\begin{array}{c}-0.008 \\
(0.9)\end{array}$ & $\begin{array}{c}-0.023 \\
(0.6)\end{array}$ & $\begin{array}{c}-0.073 \\
(0.1)\end{array}$ & $\begin{array}{c}0.014 \\
(0.7)\end{array}$ & -0.5 \\
\hline MEcyan & $\begin{array}{c}-0.0026 \\
\text { (1) }\end{array}$ & $\begin{array}{c}-0.017 \\
(0.7)\end{array}$ & $\begin{array}{c}0.028 \\
(0.5)\end{array}$ & $\begin{array}{l}-0.053 \\
(0.2)\end{array}$ & $\begin{array}{c}-0.033 \\
(0.5)\end{array}$ & $\begin{array}{c}0.11 \\
(0.01)\end{array}$ & $\begin{array}{c}-0.028 \\
(0.5)\end{array}$ & $\begin{array}{l}0.015 \\
(0.7)\end{array}$ & \\
\hline MEgreen & $\begin{array}{l}-0.01 \\
(0.8)\end{array}$ & $\begin{array}{l}-0.075 \\
(0.09)\end{array}$ & $\begin{array}{c}-0.026 \\
(0.6)\end{array}$ & $\begin{array}{c}0.034 \\
(0.4)\end{array}$ & $\begin{array}{c}-0.012 \\
(0.8)\end{array}$ & $\begin{array}{c}0.037 \\
(0.4)\end{array}$ & $\begin{array}{c}-0.062 \\
(0.2)\end{array}$ & $\begin{array}{c}-0.14 \\
(0.002)\end{array}$ & \\
\hline MEgrey & $\begin{array}{c}-0.027 \\
(0.5)\end{array}$ & $\begin{array}{c}-0.0095 \\
(0.8)\end{array}$ & $\begin{array}{c}-0.012 \\
(0.8)\end{array}$ & $\begin{array}{l}-0.043 \\
(0.3)\end{array}$ & $\begin{array}{c}-0.045 \\
(0.3)\end{array}$ & $\begin{array}{c}0.033 \\
(0.5)\end{array}$ & $\begin{array}{l}0.027 \\
(0.5)\end{array}$ & $\begin{array}{c}0.023 \\
(0.6)\end{array}$ & \\
\hline & $\begin{array}{l}\text { Pathologic } \\
\text { stage }\end{array}$ & $\begin{array}{c}\text { Pathology } \\
\text { T stage }\end{array}$ & $\begin{array}{l}\text { Pathology } \\
\text { N stage }\end{array}$ & $\begin{array}{l}\text { Pathology } \\
\text { M stage }\end{array}$ & Gender & $\begin{array}{c}\text { Radiation } \\
\text { therapy }\end{array}$ & $\begin{array}{l}\text { istologica } \\
\text { type }\end{array}$ & $\begin{array}{c}\text { Residual } \\
\text { tumor }\end{array}$ & \\
\hline
\end{tabular}

(c)

FiguRE 5: Network construction of the weighted coexpressed genes and their associations with clinical traits. (a) Hierarchical clustering tree of the TCGA-LUAD samples based on the DEGs. Dendrogram tips are labeled with the TCGA-LUAD unique name and experiment identifier. In the hierarchical dendrogram, lower branches correspond to higher coexpression (height = Euclidean distance). Identical colors in the ten bands below the dendrogram depict the TCGA-LUAD clinical traits. (b) Heat map view of topological overlap of coexpressed genes in different modules. The heat map was generated from the topological overlap values between genes. The genes were grouped into modules labeled by a color code, which are given under the gene dendrogram on both sides. The topological overlap was high among genes of same module. (c) Module-trait relationships for gender, histological type, lymphatic invasion, tumor status, treatment condition, and pathologic stage. Numbers shown represent Pearson correlations between the modules and traits. $P$ values are in parentheses. Numbers on the color bar refer to the strength of the correlation in the table (red $=1$, blue $=-1$ ). $T$, extent of the tumor; $N$, extent of spread to the lymph nodes; $M$, presence of metastasis. Figure 5 was reproduced from Sun et al. [16]. 
TABLE 3: Univariate Cox regression analysis of lightcyan module genes and overall survival*.

\begin{tabular}{lccc}
\hline Genes & & Overall survival & \\
& HR & CI (95\% CI) & $<$ value \\
\hline RRM2 & 1.291 & $1.152-1.448$ & $<0.001$ \\
RPS6KL1 & 0.798 & $0.709-0.897$ & 0.001 \\
RTL1 & 1.132 & $1.054-1.215$ & 0.002 \\
RXFP1 & 0.864 & $0.787-0.949$ & 0.004 \\
RRM1 & 1.438 & $1.121-1.845$ & 0.010 \\
RTCD1 & 1.489 & $1.100-2.014$ & 0.013 \\
RRAGB & 0.706 & $0.537-0.929$ & 0.014 \\
RSPH10B2 & 0.909 & $0.842-0.981$ & 0.017 \\
RRM2B & 0.784 & $0.641-0.958$ & 0.019 \\
RSPH9 & 0.901 & $0.826-0.983$ & 0.024 \\
RXFP2 & 0.734 & $0.562-0.960$ & 0.038 \\
RUNX1 & 0.798 & $0.645-0.988$ & \\
\hline
\end{tabular}

HR, hazard ratio; CI, confidence interval. *Association of the 61 genes of the lightcyan module with survival was analyzed using univariate Cox regression analysis. Presented in the table were those which showed significant association $(P<0.05)$.

TABLe 4: Multivariate Cox regression analysis of lightcyan module genes and overall survival* .

\begin{tabular}{lccccc}
\hline Genes & $\beta$ & HR & selogHR & $z$ & CI $(95 \% \mathrm{Cl})$ \\
\hline RRAGB & -0.2491 & 0.7795 & 0.1360 & -1.83 & $0.5971-1.0176$ \\
RSPH9 & -0.0679 & 0.9344 & 0.0462 & -1.47 & $0.8535-1.0230$ \\
RPS6KL1 & -0.2317 & 0.7932 & 0.0608 & -3.81 & $0.7042-0.8935$ \\
RTL1 & 0.1104 & 1.1167 & 0.0380 & 2.91 & $1.0367-1.2030$ \\
RXFP1 & -0.1035 & 0.9016 & 0.0497 & -2.08 & $0.8180-0.9939$ \\
RRM2 & 0.1571 & 1.1701 & 0.0626 & 2.51 & $1.0350-1.3229$ \\
\hline
\end{tabular}

*The listed genes were selected by the Akaike information criterion (AIC) model from the significant genes after the univariate Cox regression analysis (Table 3). Multivariate Cox regression analysis of association of the listed genes with survival was performed to reveal the independent predictor for survival and generate a prognostic risk score model. $\beta$, regression coefficient; HR, hazard ratio; CI, confidence interval; ${ }^{*} P<0.05$.

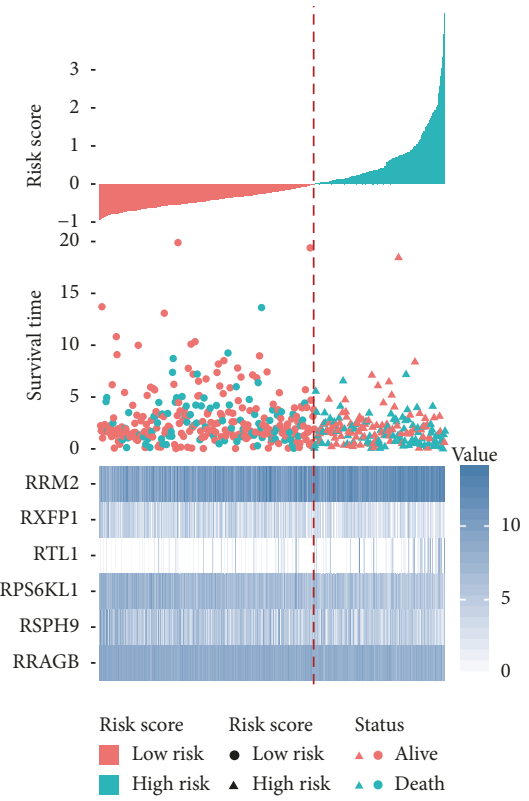

(a)

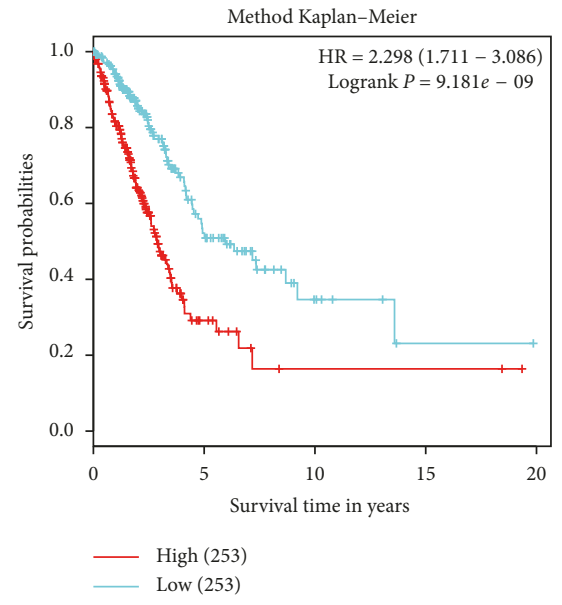

(b)

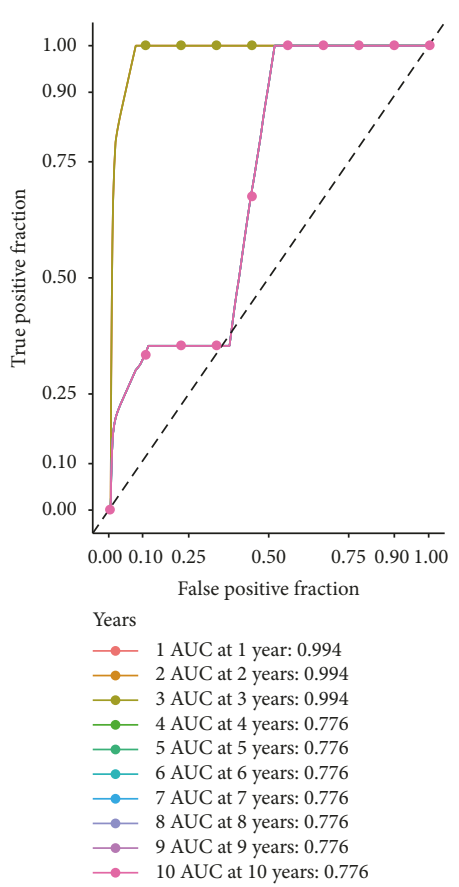

(c)

FIgURE 6: Continued. 


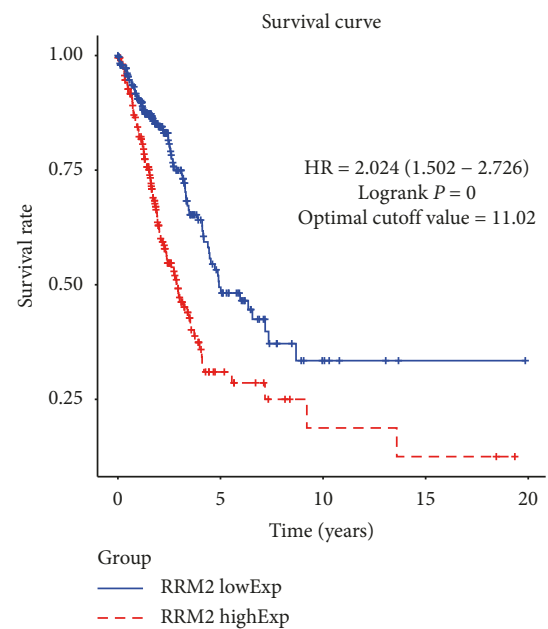

(d)

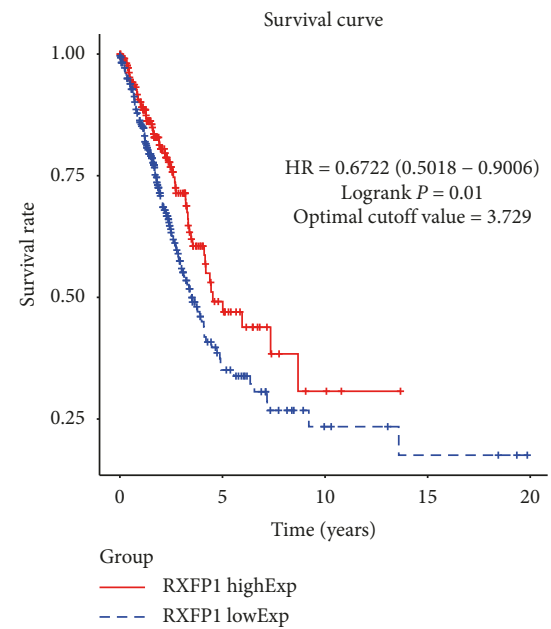

(g)

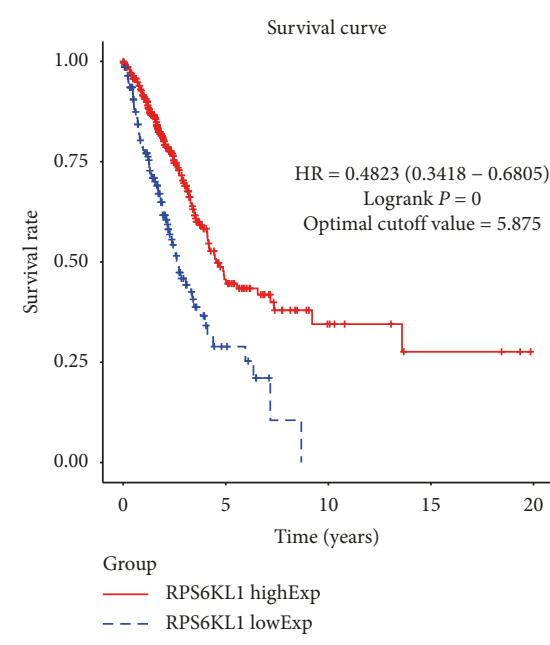

(e)

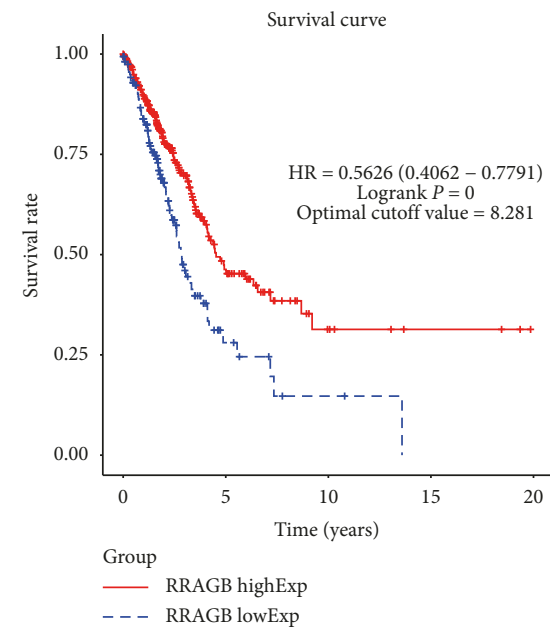

(h)

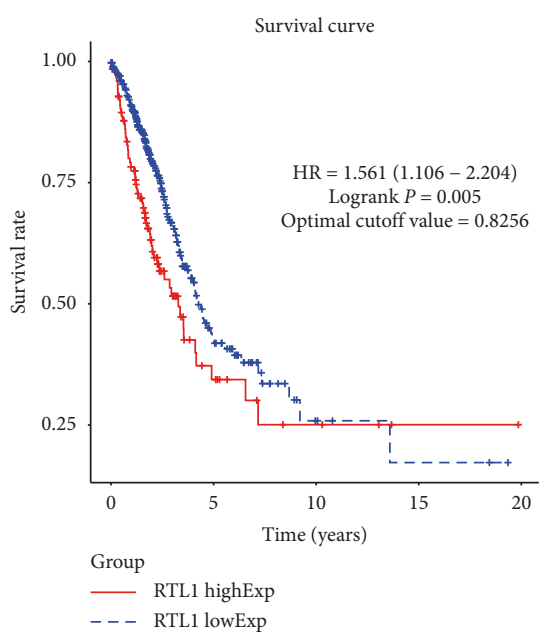

(f)

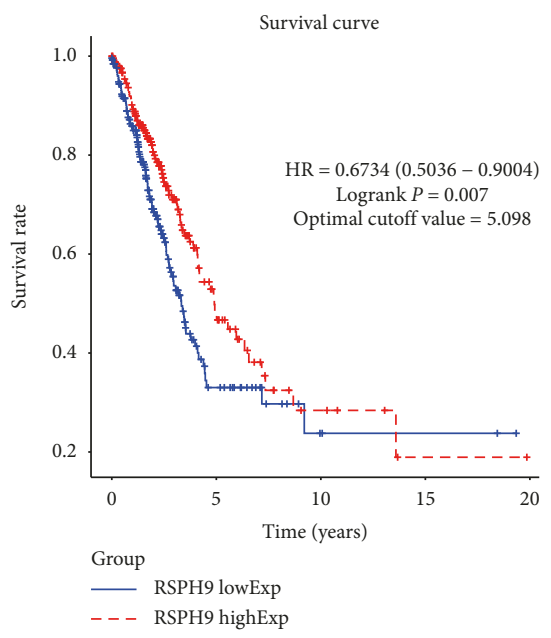

(i)

FIgURE 6: The prognostic performance of the six-gene signature in the TCGA-LUAD test cohort. (a) Risk score analysis of the six-gene signature of NSCLC. Risk score of gene signature (top); duration of cases (middle); low and high score groups for the six genes (bottom). (b) Survival analysis of the high-risk group and the low-risk group using Kaplan-Meier curves. (c) The prognostic efficiency of the six-gene signature for survival time. ROC curves of the six-gene signature for predicting 1- to 10-year survival were analyzed. (d-i) The independent prognostic efficiency of individual mRNA in the six-gene signature of the test set. (d) RRM2; (e) RPS6KL1; (f) RTL1; (g) RXFP1; (h) RRAGB; (i) RSPH9. Horizontal axis, overall survival time. Vertical axis, overall survival.

\section{Discussion}

In the current study, we have identified a six-gene prognostic model for NSCLC adenocarcinoma by calculating prognostic score using the formula: prognostic score $=$ $\left(-0.2491 \times \mathrm{EXP}_{\mathrm{RRAGB}}\right)+\left(-0.0679 \times \mathrm{EXP}_{\mathrm{RSPH} 9}\right)+(-0.2317 \times$ $\left.\mathrm{EXP}_{\mathrm{RPS} 6 \mathrm{KL} 1}\right)+\left(-0.1035 \times \mathrm{EXP}_{\mathrm{RXFP} 1}\right)+0.1571 \times \mathrm{EXP}_{\mathrm{RRM} 2}+$ $0.1104 \times \mathrm{EXP}_{\mathrm{RTL} 1}$, where EXP is the FPKM value of the mRNA included in the model. Characterization of prognostic performance revealed that the model separates NSCLC patients in the TCGA-LUAD dataset into the lowrisk score group and the high-risk score group with median prognostic score 0.972. Higher scores predicted higher risk. The area under ROC curve (AUC) was 0.994 or 0.776 in predicting the 1 - to 10 -year survival of NSCLC patients. The expression of each gene in the signature differentiates survival of NSCLC patients. The results were similar in the independent GSE11969 dataset of NSCLC adenocarcinoma. All these results support that the sixgene signature is an independent biomarker for prediction of overall survival of NSCLC adenocarcinoma.

Several expression-based gene signatures for NSCLC prognosis in the previous studies have been identified. The 8gene signature (STAT1, CLU, GTSE1, NUSAP1, ABCA8, TNNT1, ENTPD3, and CPA3) can significantly stratify patients into low- and high-risk groups and predict patients in stage II-III benefiting from adjuvant chemotherapy [24]. The independent prognostic six-protein signature (c-SRC, Cyclin E1, TTF1, p65, CHK1, and JNK1) is identified for ADC and five-protein signature (EGFR, p38 $\alpha$, AKT1, SOX2, and E-cadherin) for SCC [25]. The 15-gene signature (ATP1B1, TRIM14, FAM64A, FOSL2, HEXIM1, MB, L1CAM, UMPS, EDN3, STMN2, MYT1L, IKBKAP, MLANA, MDM2, and ZNF236) can differentiate high- and 


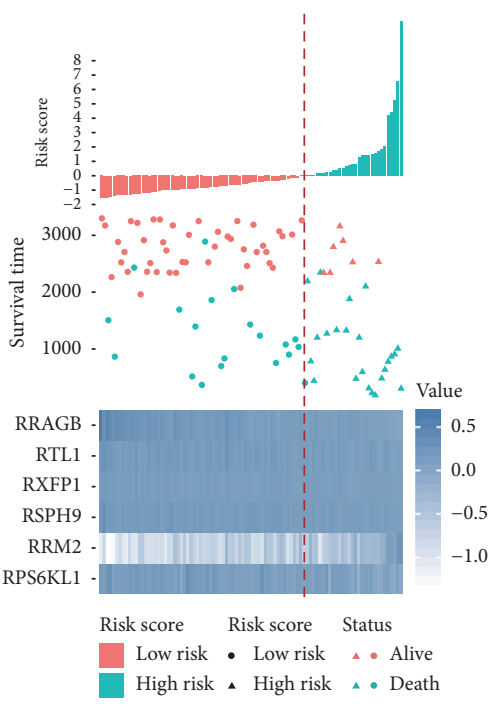

(a)

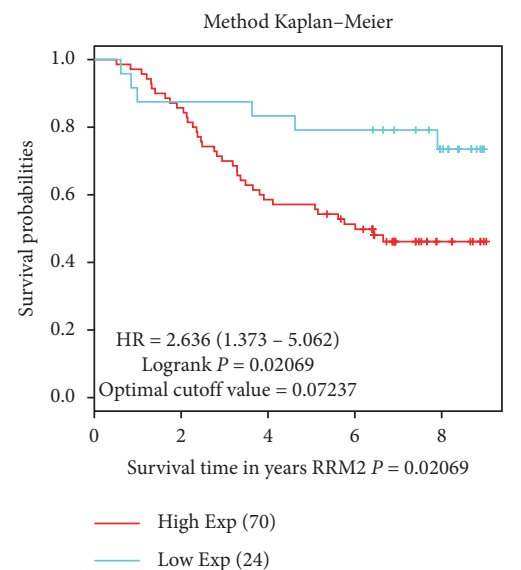

(d)

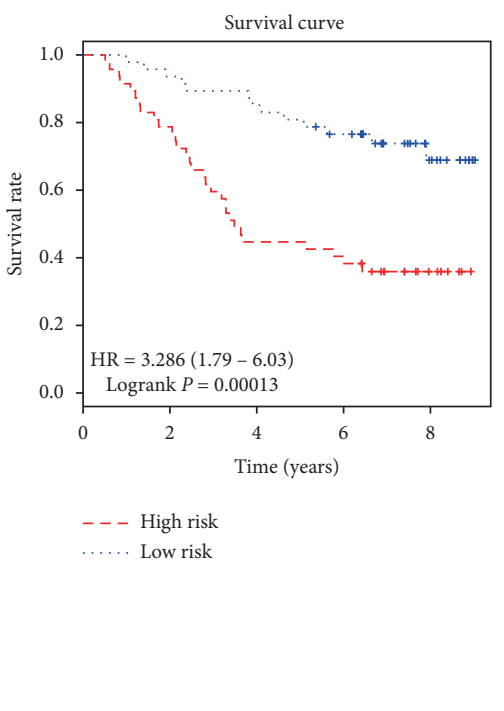

(b)

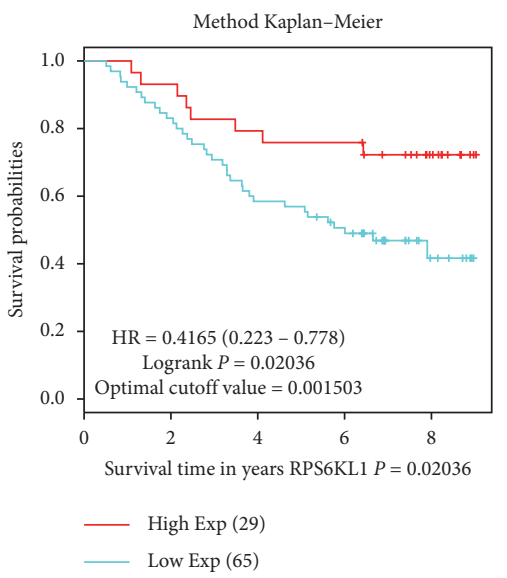

(e)

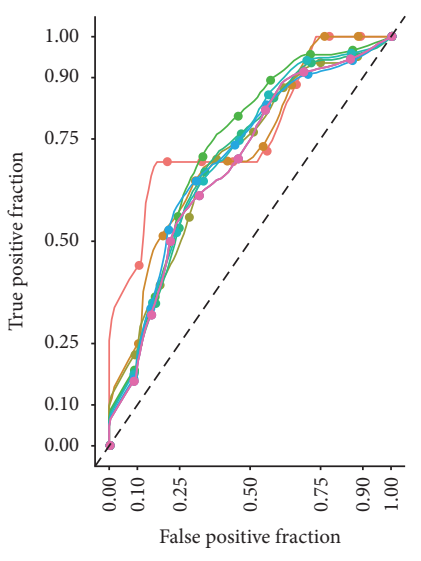

Years

$$
\begin{aligned}
& \longrightarrow 1 \text { AUC at } 1 \text { year: } 0.822 \\
& \longrightarrow \quad 2 \text { AUC at } 2 \text { years: } 0.785 \\
& \longrightarrow \quad 3 \text { AUC at } 3 \text { years: } 0.79 \\
& \longrightarrow \quad 4 \text { AUC at } 4 \text { years: } 0.808 \\
& \longrightarrow \quad 5 \text { AUC at } 5 \text { years: } 0.768 \\
& \longrightarrow \quad 6 \text { AUC at } 6 \text { year: } 0.779 \\
& \longrightarrow \quad 7 \text { AUC at } 7 \text { years: } 0.773 \\
& \longrightarrow \quad 8 \text { AUC at } 8 \text { years: } 0.755 \\
& \longrightarrow \quad 9 \text { AUC at } 9 \text { years: } 0.755 \\
& \longrightarrow \quad 10 \text { AUC at } 10 \text { years: } 0.755
\end{aligned}
$$

(c)

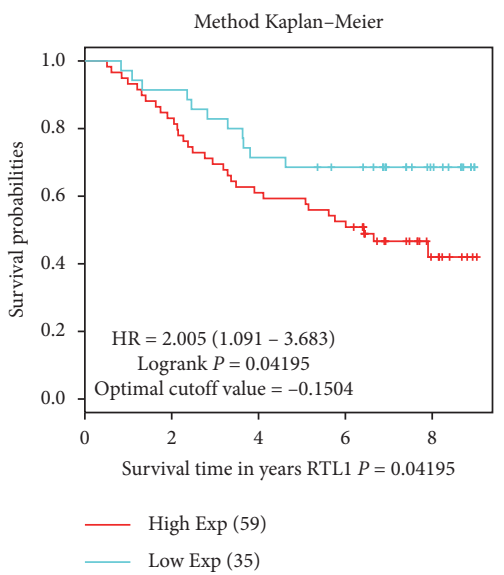

(f)

Figure 7: Continued. 


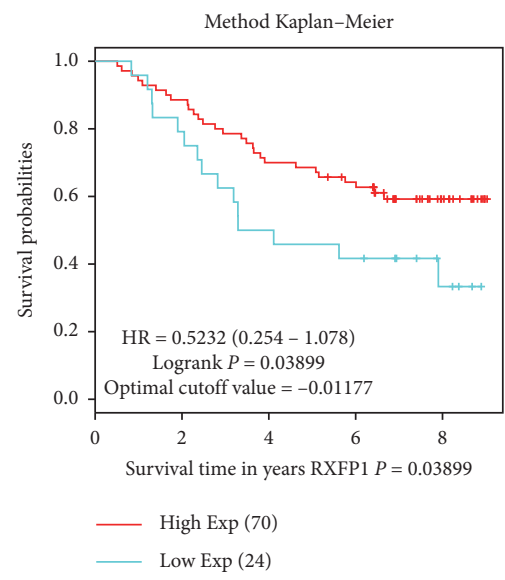

(g)

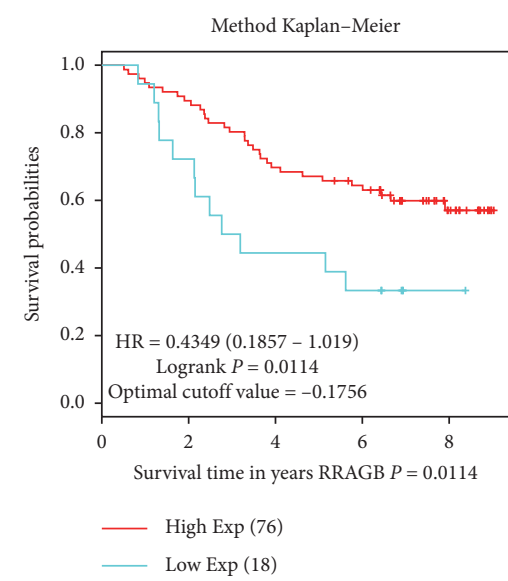

(h)

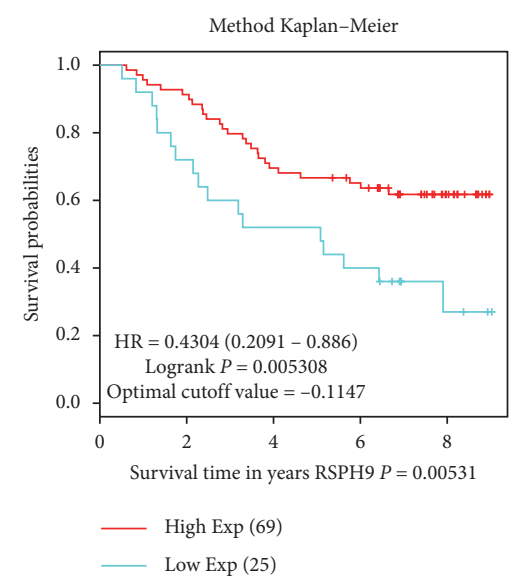

(i)

Figure 7: The prognostic performance of the six-gene signature in the GSE11969 validation cohort. (a) Risk score analysis of the six-gene signature of NSCLC. Risk score of gene signature (top); duration of cases (middle); low and high score groups for the six genes (bottom). (b) Survival analysis of the high-risk group and the low-risk group using Kaplan-Meier curves. (c) The prognostic efficiency of the six-gene signature for survival time. ROC curves of the six-gene signature for predicting 1- to 10-year survival were analyzed. (d-i) The independent prognostic efficiency of individual mRNA in the six-gene signature in the validation set. (d) RRM2; (e) RPS6KL1; (f) RTL1; (g) RXFP1; (h) RRAGB; (i) RSPH9. Horizontal axis, overall survival time. Vertical axis, overall survival.

low-risk subgroups with significantly different overall survival and is prognostic for both adenocarcinoma and squamous cell carcinoma cases [8]. The multigene RNA expression signature GeneFx ${ }^{\circledR}$ Lung classifies early-stage NSCLC patients as high-risk or low-risk for disease recurrence and predicts the overall survival [9]. The 50-gene signature novel scoring system is identified for tumor-infiltrating immune cells with strong correlation with clinical outcome of stage I/II non-small-cell lung cancer [26]. The 6gene signature (ABCC4, ADRBK2, KLHL23, PDS5A, UHRF1, and ZNF551) is identified for independent prognosis of overall survival [10]. The Yin Yang Expression Ratio Signature containing 10 functionally opposing genes (GRM1, IGFBP5, NRAS, and RECQL4 in the Yin group and CRIP2, CD83, GATA2, HOXA5, SOSTDC1, and TNNC1 in the Yang group) significantly separates high- and low-risk patients with stage IA or IB adenocarcinoma and squamous cell carcinomas of all stages and can predict the benefit of adjuvant chemotherapy in high-risk patients with stage I NSCLC [11]. The 14-gene signature (11 cancer-related genes BAG1, BRCA1, CDC6, CDK2AP1, ERBB3, FUT3, IL11, LCK, $R N D 3, S H 3 B G R$, and $W N T 3 A$ and three reference genes $E S D$, TBP, and YAP1) predicts survival in resected nonsquamous, non-small-cell lung cancer [4], identifies patients at high risk of mortality despite small, node-negative lung tumors [5], improves identification of patients at risk for recurrence in early-stage none small cell lung cancer [6], and predicts benefit from adjuvant chemotherapy for very early stage NSCLC and is superior over current NCCN criteria at identifying high-risk patients [7]. The 17-gene panel consisting of genes involved in epithelial-mesenchymal transition (EMT), hypoxia response, glycometabolism, and epigenetic modifications for non-small-cell lung cancer prognosis is identified through integrative epigenomictranscriptomic analyses and clearly stratifies NSCLC patients with significant differences in overall survival [12]. Our six-gene prognostic signature for NSCLC adenocarcinoma include RRAGB, RSPH9, RPS6KL1, RXFP1, RRM2, and RTL1 genes which are not contained in the previous gene signatures. Therefore, our six-gene signature is likely a novel tool for NSCLC adenocarcinoma prognosis.

Our data indicated that high expression of RRAGB, RSPH9, RPS6KL1, and RXFP1 and low expression of RTL1 and RRM2 predicted good survival. Among these six genes, we found that RRM2 (ribonucleotide reductase regulatory subunit $\mathrm{M} 2$ and ribonucleoside-diphosphate reductase subunit M2) is overexpressed in NSCLC tissues. The RRM2 mRNA levels are higher in the high-risk group than those in the low-risk group and may differentiate the survival of NSCLC patients. Studies have shown that RRM2 is known as a marker that may be involved in predicting clinical response to gemcitabine plus docetaxel [27] and predicting the treatment response to platinumbased chemotherapy and survival $[28,29]$ in non-smallcell lung cancer patients. The expression levels of RRM2 and differences between primary tumors and infiltrated regional lymph nodes were correlated with relapse-free survival (RFS) and overall survival (OS) in patients with resectable non-small-cell lung cancer [30]. RRM2 regulates antiapoptotic protein $\mathrm{Bcl}-2$ in head and neck and lung cancers [31, 32]. BRCA1-regulated RRM2 expression protects glioblastoma cells from endogenous replication stress and promotes tumorigenicity [33]. RRM2 is regulated by the transforming growth factor beta regulator 4 (TBRG4) gene which affects tumorigenesis in human H1299 lung cancer cells [34]. It is likely that RRM2 plays an essential role in NSCLC development and progression and may serve as a key marker for NSCLC prognosis.

The model signature genes RSPH9, RPS6KL1, RXFP1, and RTL1 have been revealed to be involved in cancer 


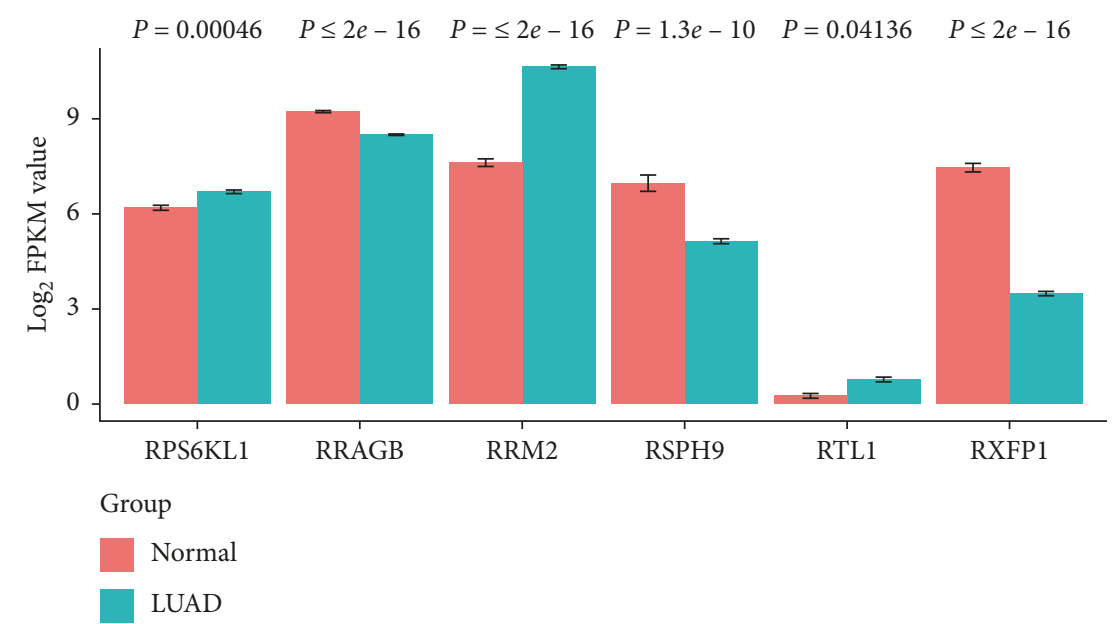

(a)

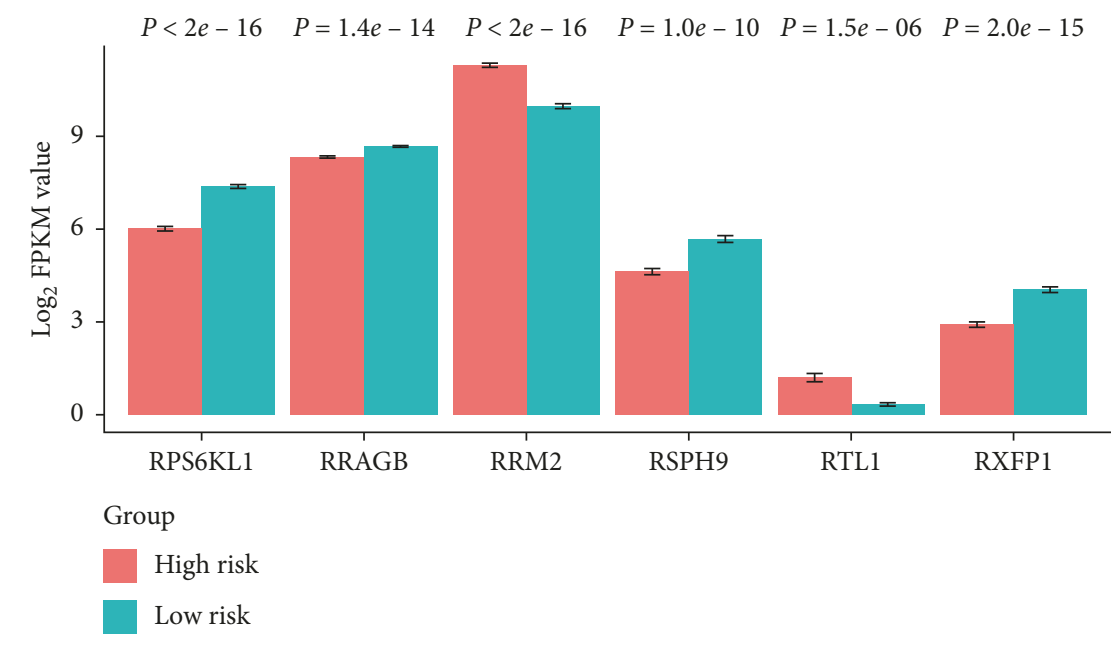

(b)

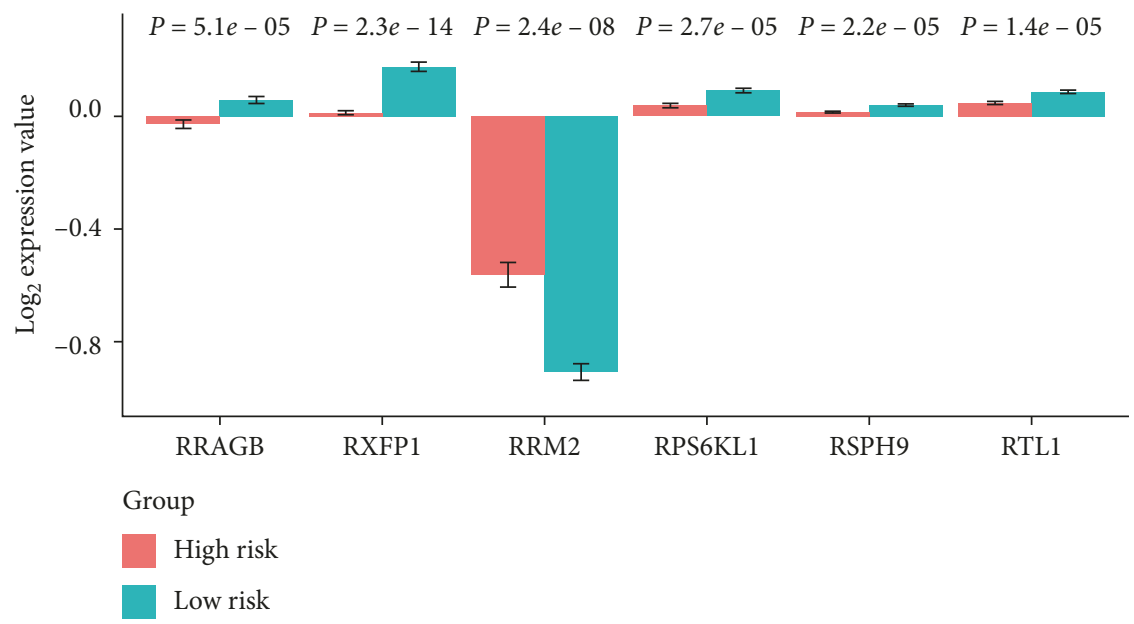

(c)

Figure 8: The relative levels of RRAGB, RSPH9, RPS6KL1, RXFP1, RRM2, and RTL1 in NSCLC adenocarcinoma. (a) Compared with the normal control, RRAGB, RSPH9, and RXFP1 mRNA levels were significantly decreased and RPS6KL1, RTL1, and RRM2 mRNA levels were significantly increased in NSCLC of TCGA-LUAD. (b) The expression levels of RRAGB, RSPH9, RPS6KL1, and RXFP1 were significantly lower and RTL1 and RRM2 mRNA levels were significantly higher in the high-risk group than those in the low-risk group of TCGA-LUAD. (c) The expression levels of RRAGB, RSPH9, RPS6KL1, RXFP1, and RTL1 were significantly lower and RRM2 mRNA levels was significantly higher in the high-risk group than those in the low-risk group in NSCLC adenocarcinoma of GSE11969. 
activity. RSPH9 (radial spoke head 9 homolog) was significantly hypermethylated and downregulated in the hepatocellular carcinoma (HCC) and epigenetic silencing of RSPH9 may be associated with hepatocellular carcinoma [35]. In multivariate regression analysis, hypermethylation of RSPH9 was an independent predictor of non-muscle invasive bladder cancer (NMIBC) recurrence and progression, and RSPH9 could be of value for the assessment of disease recurrence and progression and for clinical decisionmaking regarding treatment [36]. RPS6KL1 (ribosomal protein S6 kinase-like 1) mutation hot spots were confirmed and validated in colorectal cancers with microsatellite instability, which might be used to develop personalized tumor profiling and therapy [37]. RXFP1 (relaxin family peptide receptor 1 , relaxin receptor 1 , and relaxin/insulin-like family peptide receptor 1) is a $G$ protein-coupled receptor with the extracellular low-density lipoprotein A (LDL-A) module located at the N-terminus. Studies have revealed that RXFP1 is activated by both Clq-tumor necrosis factor-related protein 8 (CTRP8) and relaxin and contributes to growth and invasion of human glioblastoma [38-40]. Suppression of RXFP1 inhibits prostate cancer tumorigenesis, growth, and metastasis [41-43]. Relaxin 2/RXFP1 Signalling induces cell invasion via the beta-catenin pathway in endometrial cancer [44]. Expression of RXFP1 is decreased in idiopathic pulmonary fibrosis [45] and mediates the effects of miR$144-3 p$ in lung fibroblasts from patients with idiopathic pulmonary fibrosis [46]. RXFP1 protects against airway fibrosis during homeostasis but not against fibrosis associated with chronic allergic airways disease [47]. RTL1 (retrotransposon-like protein 1, retrotransposon Gag like 1, also known as Peg11, paternally expressed 11) is essential for maintenance of the fetal capillaries. Both its loss and its overproduction cause late-fetal and/or neonatal lethality in mice [48]. The Rtl1 promoter is hypermethylated in the placentas with fetal growth restriction. Infants with severe SGA have abnormal placental DNA methylation of CpG1 in the CG4 region of RTL1, suggesting the existence of disturbed epigenetic control in utero [49]. Overexpression of RTL1 in melanoma cells accelerated cutaneous melanoma cell proliferation, promoted the passage of the cell cycle beyond G1 phase, and increased the expression of cell cycle related genes, and RTL1 promotes melanoma cell proliferation by regulating the $\mathrm{Wnt} / \beta$-Catenin signalling pathway [50]. RTL1 activation serves as a driver of HCC. Overexpression of RTL1 was detected in $30 \%$ of analyzed human HCC samples, indicating the potential relevance of this locus as a therapeutic target for patients [51]. RRAGB (Ras related GTP binding B) mediates mTOR (mechanistic target of rapamycin kinase) and TRIM37 (tripartite motif containing 37) pathways related to amino acid-stimulated MTORC1 (MTOR complex 1) signalling and autophagy [52]. In the current study, we found that RRAGB, RSPH9, RPS6KL1, RXFP1, and RTL1 are differentially expressed between NSCLC and ANTs. Expression of RRAGB, RSPH9, RPS6KL1, RXFP1, and RTL1 is significantly associated with survival of NSCLC. These results suggest that RRAGB, RSPH9, RPS6KL1, RXFP1, and RTL1 may be key factors in NSCLC activity.

\section{Limitations}

(1) The relative expression profiles of RTL1 expression in the TCGA-LUAD and GSE11969 of NSCLC adenocarcinoma are not consistent. This may be due to intervariation between different detection platforms. (2) The six-gene prognostic signature remains to be evaluated for clinical application using multicenter randomized controlled studies and mechanistic investigation using in vivo and in vitro experiments.

\section{Conclusions}

In summary, we have identified a six-gene prognostic model for NSCLC adenocarcinoma by calculating prognostic-score using the formula: prognostic score $=\left(-0.2491 \times \mathrm{EXP}_{\text {RRAGB }}\right)$ $+\left(-0.0679 \times \mathrm{EXP}_{\mathrm{RSPH}}\right)+\left(-0.2317 \times \mathrm{EXP}_{\mathrm{RPS} 6 \mathrm{KL} 1}\right)+(-0.1035 \times$ $\left.\mathrm{EXP}_{\mathrm{RXFP1}}\right)+0.1571 \times \mathrm{EXP}_{\mathrm{RRM} 2}+0.1104 \times \mathrm{EXP}_{\mathrm{RTL}}$, where $\mathrm{EXP}$ is the FPKM value of the mRNA included in the model. This signature and the genes RRAGB, RSPH9, RPS6KL1, RXFP1, RRM2, and RTL1 included in this model are independent biomarkers for prediction of overall survival of NSCLC adenocarcinoma. The role of the signature genes played in NSCLC adenocarcinoma activity and prognosis remains to be investigated in the future.

\section{Abbreviations}

LC: $\quad$ Lung cancer

NSCLC: Non-small-cell lung cancer

ANT: Adjacent normal tissue

WGCNA: Weighted gene coexpression network analysis

TCGA: The Cancer Genome Atlas

DEGs: Differentially expressed genes

HR: $\quad$ Hazard ratio

AUC: Area under the curve

GEO: Gene Expression Omnibus

GSE: Gene expression data series

LIMMA: Linear models for microarray analysis

QC: $\quad$ Quality control

SD: $\quad$ Standard deviation

TOM: Topological Overlap Matrix

ME: $\quad$ Module eigengene

KEGG: Kyoto Encyclopedia of Genes and Genomes

AJCC: American Joint Committee on Cancer

PCC: Pearson's correlation coefficient

PCA: $\quad$ Principal component analysis

ROC: Receiver operating characteristic

David: The Database for Annotation, Visualization, and Integrated Discovery

LUAD: Lung adenocarcinoma

NCCN: National Comprehensive Cancer Network

EMT: Epithelial-mesenchymal transition

FPKM: Fragments per kilobase million.

\section{Data Availability}

The data used to support the findings of this study are included within the article. 


\section{Conflicts of Interest}

The authors declare that there are no conflicts of interest regarding the publication of this article.

\section{Authors' Contributions}

Hui Xie and Conghua Xie participated in the research design. Hui Xie performed the data analysis. Hui Xie wrote or contributed to the writing of the manuscript.

\section{Acknowledgments}

The authors thank the Cancer Genome Atlas and the Gene Expression Omnibus for providing the data for this study. This study was supported by the National Natural Science Foundation of China (81372498, 81572967, and 81773236), National Project for Improving the Ability of Diagnosis and Treatment of Difficult Diseases, National Key Clinical Speciality Construction Program of China ([2013]544), the Fundamental Research Funds for the Central Universities (2042018kf1037 and 2042019kf0329), Health Commission of Hubei Province Scientific Research Project (WJ2019H002), Wuhan City Huanghe Talents Plan, and Zhongnan Hospital of Wuhan University Science, Technology and Innovation Seed Fund (znpy2016050 and znpy2017049).

\section{References}

[1] F. Bray, J. Ferlay, I. Soerjomataram, R. L. Siegel, L. A. Torre, and A. Jemal, "Global cancer statistics 2018: GLOBOCAN estimates of incidence and mortality worldwide for 36 cancers in 185 countries," CA: A Cancer Journal for Clinicians, vol. 68, no. 6, pp. 394-424, 2018.

[2] L. A. Torre, F. Bray, R. L. Siegel, J. Ferlay, J. Lortet-Tieulent, and A. Jemal, "Global cancer statistics, 2012," CA: A Cancer Journal for Clinicians, vol. 65, no. 2, pp. 87-108, 2015.

[3] R. S. Herbst, J. V. Heymach, and S. M. Lippman, "Lung cancer," New England Journal of Medicine, vol. 359, no. 13, pp. 1367-1380, 2008.

[4] J. R. Kratz, J. He, S. K. Van Den Eeden et al., "A practical molecular assay to predict survival in resected non-squamous, non-small-cell lung cancer: development and international validation studies," The Lancet, vol. 379, no. 9818, pp. 823-832, 2012.

[5] J. R. Zhi, S. K. Van den Eeden, J. He, D. M. Jablons, and M. J. Mann, "A prognostic assay to identify patients at high risk of mortality despite small, node-negative lung tumors," JAMA, vol. 308, no. 16, pp. 1629-1631, 2012.

[6] G. A. Woodard, M. A. Gubens, T. M. Jahan et al., "Prognostic molecular assay might improve identification of patients at risk for recurrence in early-stage non-small-cell lung cancer," Clinical Lung Cancer, vol. 15, no. 6, pp. 426-432, 2014.

[7] G. A. Mann, S. X. Wang, J. R. Kratz et al., "Adjuvant chemotherapy guided by molecular profiling and improved outcomes in early stage, non-small-cell lung cancer," Clinical Lung Cancer, vol. 19, no. 1, pp. 58-64, 2018.

[8] S. D. Jablons, J. Sykes, M. Pintilie et al., "Validation of a histology-independent prognostic gene signature for earlystage, non-small-cell lung cancer including stage IA patients," Journal of Thoracic Oncology, vol. 9, no. 1, pp. 59-64, 2014.
[9] S. Der, C. Q. Zhu, S. Brower, and A. Uihlein, "Predicting prognosis of early-stage non-small cell lung cancer using the GeneFx ${ }^{\circledR}$ lung signature,” PLoS Currents, vol. 7, 2015.

[10] P. Huang, C. L. Cheng, Y. H. Chang et al., "Molecular gene signature and prognosis of non-small cell lung cancer," Oncotarget, vol. 7, no. 32, pp. 51898-51907, 2016.

[11] W. Xu, G. Jia, J. R. Davie, L. Murphy, R. Kratzke, and S. Banerji, "A 10-gene Yin Yang expression ratio signature for stage IA and IB non-small cell lung cancer," Journal of Thoracic Oncology, vol. 11, no. 12, pp. 2150-2160, 2016.

[12] Y. L. Chen, Y. Zhang, J. Wang et al., "A 17 gene panel for nonsmall cell lung cancer prognosis identified through integrative epigenomic-transcriptomic analyses of hypoxia-induced epithelial-mesenchymal transition," Molecular Oncology, vol. 13, no. 7, pp. 1490-1502, 2019.

[13] D. H. Heiland, G. Haaker, D. Delev et al., "Comprehensive analysis of PD-L1 expression in glioblastoma multiforme," Oncotarget, vol. 8, no. 26, pp. 42214-42225, 2017.

[14] D. H. Heiland, T. Demerath, E. Kellner et al., "Molecular differences between cerebral blood volume and vessel size in glioblastoma multiforme," Oncotarget, vol. 8, no. 7, pp. 11083-11093, 2017.

[15] J. Zhang, M. Baddoo, C. Han et al., "Gene network analysis reveals a novel 22-gene signature of carbon metabolism in hepatocellular carcinoma," Oncotarget, vol. 7, no. 31, pp. 49232-49245, 2016.

[16] M. Sun, T. Sun, Z. He, and B. Xiong, "Identification of two novel biomarkers of rectal carcinoma progression and prognosis via co-expression network analysis," Oncotarget, vol. 8, no. 41, pp. 69594-69609, 2017.

[17] M. Sun, D. Wu, K. Zhou et al., "An eight-lncRNA signature predicts survival of breast cancer patients: a comprehensive study based on weighted gene co-expression network analysis and competing endogenous RNA network," Breast Cancer Research and Treatment, vol. 175, no. 1, pp. 59-75, 2019.

[18] X. Gu, D. D. Kang, K. Shen et al., "An R package suite for microarray meta-analysis in quality control, differentially expressed gene analysis and pathway enrichment detection," Bioinformatics, vol. 28, no. 19, pp. 2534-2536, 2012.

[19] J. Kaminski, M. Lacher, M. Rottenkolber et al., "Altered expression of imprinted genes in Wilms tumors," Oncology Reports, vol. 25, no. 3, pp. 817-823, 2011.

[20] C. Qi, L. Hong, Z. Cheng, and Q. Yin, "Identification of metastasis-associated genes in colorectal cancer using metaDE and survival analysis," Oncology Letters, vol. 11, no. 1, pp. 568-574, 2016.

[21] G. C. Tseng, D. Ghosh, and E. Feingold, "Comprehensive literature review and statistical considerations for microarray meta-analysis," Nucleic Acids Research, vol. 40, no. 9, pp. 3785-3799, 2012.

[22] K. Oros Klein, K. Oualkacha, M. H. Lafond, S. Bhatnagar, P. N. Tonin, and C. M. Greenwood, "Gene coexpression analyses differentiate networks associated with diverse cancers harboring TP53 missense or null mutations," Frontiers in Genetics, vol. 7, p. 137, 2016.

[23] M. A. Hossain, M. Kocan, S. T. Yao et al., "A single-chain derivative of the relaxin hormone is a functionally selective agonist of the G protein-coupled receptor, RXFP1," Chemical Science, vol. 7, no. 6, pp. 3805-3819, 2016.

[24] M. Summers, T. G. Choi, M. N. Nguyen et al., "An 8-gene signature for prediction of prognosis and chemoresponse in non-small cell lung cancer," Oncotarget, vol. 7, no. 52, pp. 86561-86572, 2016. 
[25] B. F. Jin, F. Yang, X. M. Ying et al., "Signaling protein signature predicts clinical outcome of non-small-cell lung cancer," BMC Cancer, vol. 18, no. 1, p. 259, 2018.

[26] S. Hernández-Prieto, A. Romera, M. Ferrer et al., "A 50-gene signature is a novel scoring system for tumor-infiltrating immune cells with strong correlation with clinical outcome of stage I/II non-small cell lung cancer," Clinical and Translational Oncology, vol. 17, no. 4, pp. 330-338, 2015.

[27] I. Hernando, C. Papadaki, P. Mendez et al., "Tumor BRCA1, RRM1 and RRM2 mRNA expression levels and clinical response to first-line gemcitabine plus docetaxel in non-smallcell lung cancer patients," PLoS One, vol. 3, no. 11, Article ID e3695, 2008.

[28] L. Georgoulias, L. Meng, X.-W. Wang, G.-Y. Ma, and J.-H. Chen, "Expression of RRM1 and RRM2 as a novel prognostic marker in advanced non-small cell lung cancer receiving chemotherapy," Tumor Biology, vol. 35, no. 3, pp. 1899-1906, 2014.

[29] H. Zhao, H. Zhang, Y. Du, and X. Gu, "Prognostic significance of BRCA1, ERCC1, RRM1, and RRM2 in patients with advanced non-small cell lung cancer receiving chemotherapy," Tumor Biology, vol. 35, no. 12, pp. 12679-12688, 2014.

[30] K. Tryfonidis, C. Papadaki, S. Assele et al., "Association of BRCA1, ERCC1, RAP80, PKM2, RRM1, RRM2, TS, TSP1, and TXR1 mRNA expression levels between primary tumors and infiltrated regional lymph nodes in patients with resectable non-small cell lung cancer," The Pharmacogenomics Journal, vol. 19, no. 1, pp. 15-24, 2019.

[31] J. D. Heidel, J. Y.-C. Liu, Y. Yen et al., "Potent siRNA inhibitors of ribonucleotide reductase subunit RRM2 reduce cell proliferation in vitro and in vivo," Clinical Cancer Research, vol. 13, no. 7, pp. 2207-2215, 2007.

[32] M. A. Rahman, A. R. M. R. Amin, D. Wang et al., "RRM2 regulates Bcl-2 in head and neck and lung cancers: a potential target for cancer therapy," Clinical Cancer Research, vol. 19, no. 13 , pp. 3416-3428, 2013.

[33] R. D. Shin, M. K. Gajjar, L. Tuckova et al., "BRCA1-regulated RRM2 expression protects glioblastoma cells from endogenous replication stress and promotes tumorigenicity," Nature Communications, vol. 7, no. 1, Article ID 13398, 2016.

[34] A. Wang, C. Zhao, X. Liu et al., "Knockdown of TBRG4 affects tumorigenesis in human H1299 lung cancer cells by regulating DDIT3, CAV1 and RRM2," Oncology Letters, vol. 15, no. 1, pp. 121-128, 2018.

[35] N. Yamada, K. Yasui, O. Dohi et al., "Genome-wide DNA methylation analysis in hepatocellular carcinoma," Oncology Reports, vol. 35, no. 4, pp. 2228-2236, 2016.

[36] H.-Y. Yamaguchi, Y.-J. Kim, J. S. Kim et al., "RSPH9 methylation pattern as a prognostic indicator in patients with non-muscle invasive bladder cancer," Oncology Reports, vol. 35, no. 2, pp. 1195-1203, 2016.

[37] A. E. Gylfe, J. Kondelin, M. Turunen et al., "Identification of candidate oncogenes in human colorectal cancers with microsatellite instability," Gastroenterology, vol. 145, no. 3, pp. 540-543, 2013.

[38] A. Lehtonen, U. Kunanuvat, J. Stetefeld et al., "C1q-tumour necrosis factor-related protein 8 (CTRP8) is a novel interaction partner of relaxin receptor RXFP1 in human brain cancer cells," The Journal of Pathology, vol. 231, no. 4, pp. 466-479, 2013.

[39] T. Hombach-Klonisch, A. Glogowska, M. Burg et al., "RXFP1 is targeted by complement C1q tumor necrosis factor-related factor 8 in brain cancer," Frontiers in Endocrinology, vol. 6, p. 127, 2015.
[40] T. Klonisch, A. Glogowska, T. Thanasupawat et al., "Structural commonality of C1q TNF-related proteins and their potential to activate relaxin/insulin-like family peptide receptor 1 signalling pathways in cancer cells," British Journal of Pharmacology, vol. 174, no. 10, pp. 1025-1033, 2017.

[41] S. Feng, I. U. Agoulnik, A. Truong et al., "Suppression of relaxin receptor RXFP1 decreases prostate cancer growth and metastasis," Endocrine-Related Cancer, vol. 17, no. 4, pp. 1021-1033, 2010.

[42] S. Ittmann and A. I. Agoulnik, "Expression of LDL-A module of relaxin receptor in prostate cancer cells inhibits tumorigenesis," International Journal of Oncology, vol. 39, no. 6, pp. 1559-1565, 2011.

[43] S. Feng, I. U. Agoulnik, Z. Li et al., "Relaxin/RXFP1 signaling in prostate cancer progression," Annals of the New York Academy of Sciences, vol. 1160, no. 1, pp. 379-380, 2009.

[44] M. Fue, Y. Miki, K. Takagi et al., "Relaxin 2/RXFP1 signaling induces cell invasion via the beta-catenin pathway in endometrial cancer," International Journal of Molecular Sciences, vol. 19, no. 8, 2018.

[45] J. Tan, J. R. Tedrow, J. A. Dutta et al., "Expression of RXFP1 is decreased in idiopathic pulmonary fibrosis. Implications for relaxin-based therapies," American Journal of Respiratory and Critical Care Medicine, vol. 194, no. 11, pp. 1392-1402, 2016.

[46] H. Kaminski, J. Tan, J. A. Dutta et al., "MicroRNA-144-3p targets relaxin/insulin-like family peptide receptor 1 (RXFP1) expression in lung fibroblasts from patients with idiopathic pulmonary fibrosis," Journal of Biological Chemistry, vol. 294, no. 13, pp. 5008-5022, 2019.

[47] C. S. Kass, S. G. Royce, B. Chen et al., "Relaxin family peptide receptor-1 protects against airway fibrosis during homeostasis but not against fibrosis associated with chronic allergic airways disease," Endocrinology, vol. 150, no. 3, pp. 1495-1502, 2009.

[48] Y. Sekita, H. Wagatsuma, K. Nakamura et al., "Role of retrotransposon-derived imprinted gene, Rtl1, in the feto-maternal interface of mouse placenta," Nature Genetics, vol. 40, no. 2, pp. 243-248, 2008.

[49] K. Ogata, K. Nishida, M. Ashina et al., "DNA methylation of the Rtll promoter in the placentas with fetal growth restriction," Pediatrics \& Neonatology, vol. 60, no. 5, pp. 512516, 2019.

[50] G. Fan, D. Ye, S. Zhu et al., "RTL1 promotes melanoma proliferation by regulating Wnt/beta-catenin signalling," Oncotarget, vol. 8, no. 62, pp. 106026-106037, 2017.

[51] J. D. Riordan, V. W. Keng, B. R. Tschida et al., "Identification of rtl1, a retrotransposon-derived imprinted gene, as a novel driver of hepatocarcinogenesis," PLoS Genetics, vol. 9, no. 4, Article ID e1003441, 2013.

[52] W. Largaespada, Z. Xia, J.-C. Farré, and S. Subramani, "TRIM37 deficiency induces autophagy through deregulating the MTORC1-TFEB axis," Autophagy, vol. 14, no. 9, pp. 1574-1585, 2018. 


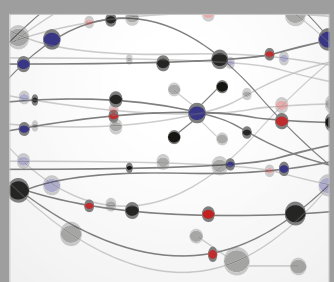

The Scientific World Journal
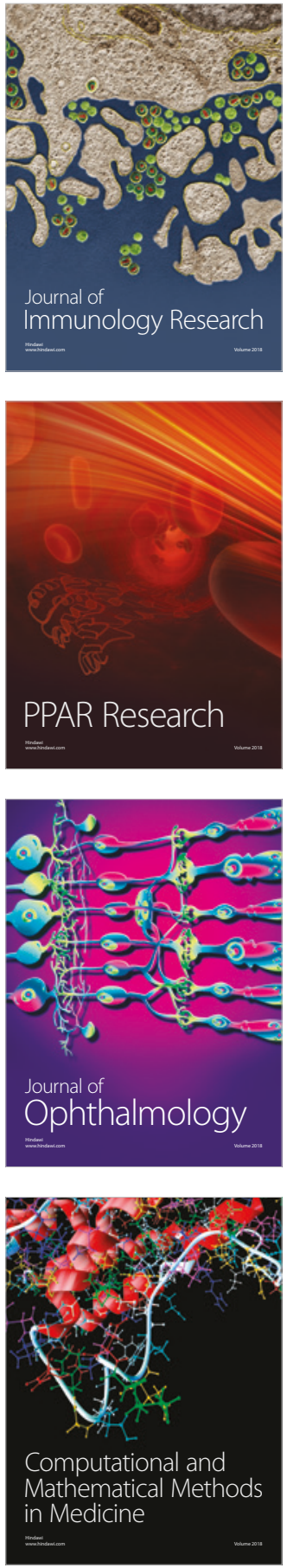

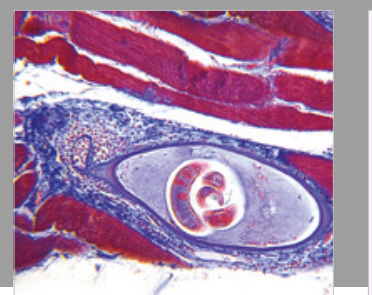

Gastroenterology Research and Practice

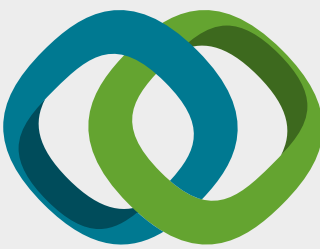

\section{Hindawi}

Submit your manuscripts at

www.hindawi.com
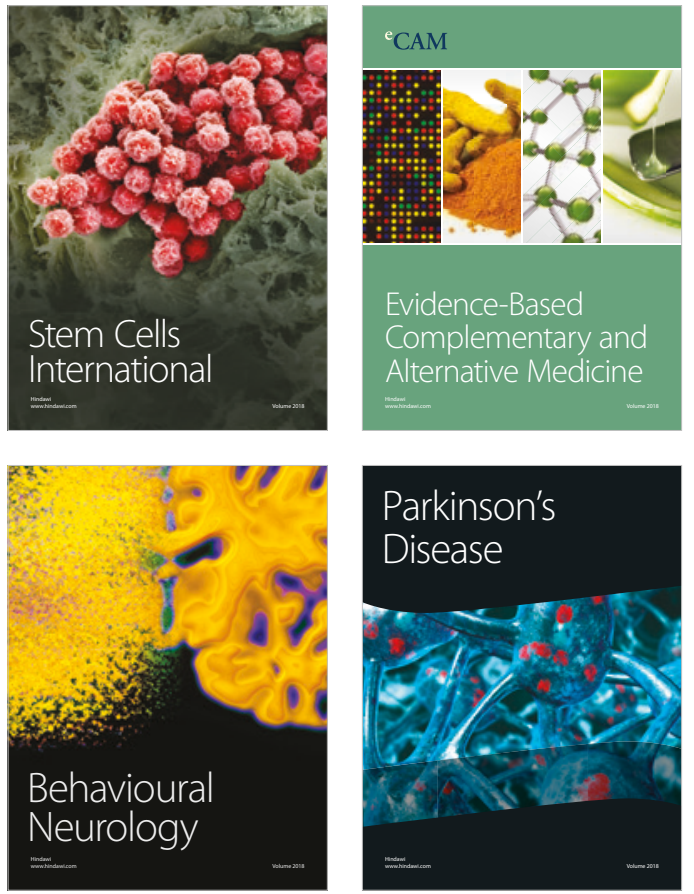

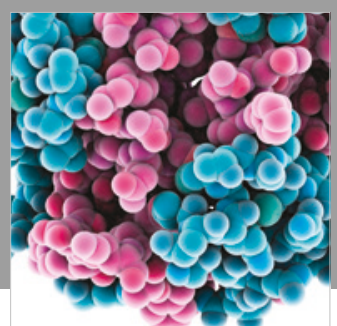

ournal of

Diabetes Research

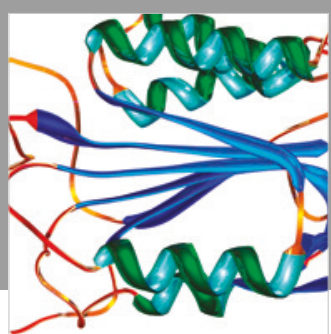

Disease Markers
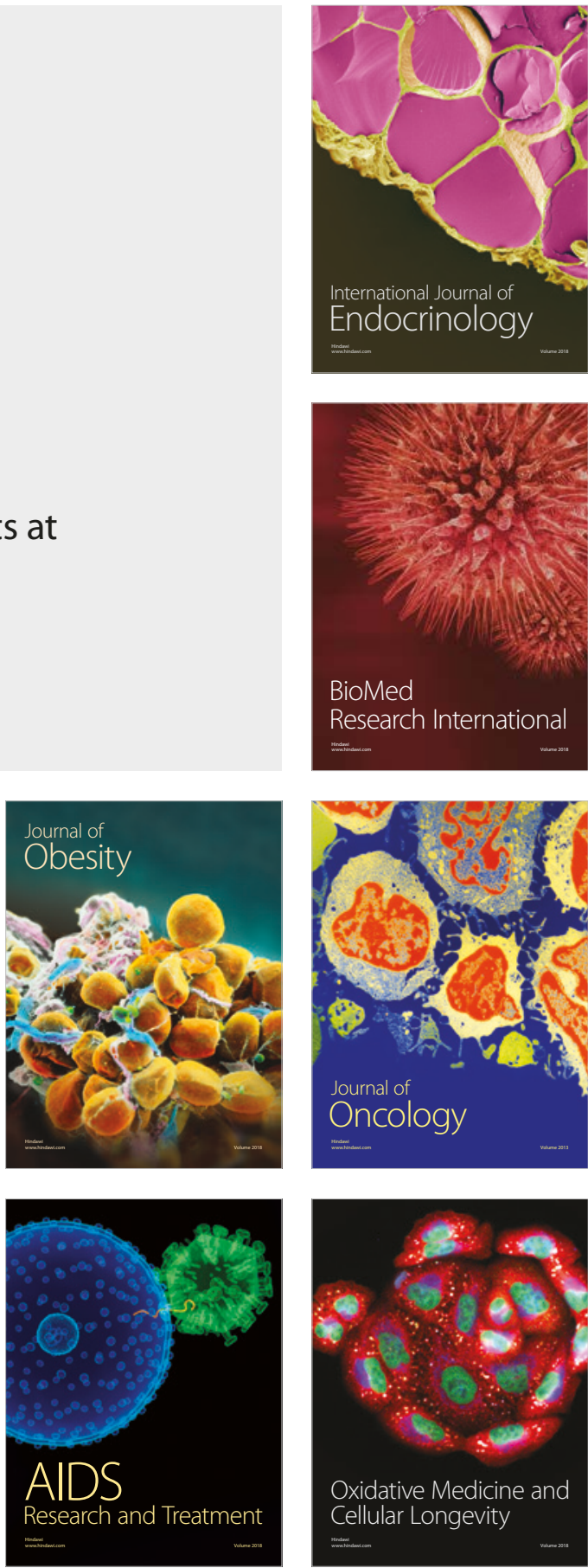